\title{
الألعاب الإكترونية وعلاقتها بالنمو الاجتماعي عند الأطفال من وجهة نظر الأهالي
}

\author{
إعداد \\ د. دانيا منير الثنواني \\ أ.شهر إبراهيم المفلح
}

كلية التربية-الطقولة المبكرة

DOI : 10.12816/0053078

مجلة الدراسات التربوية والانسانية ـ كلية التربية ـ جامعة دمنهور المجلد العاشر - العدد الثانى - لسنة 2018 
الألعاب الإكترونية وعلاقتها بالنمو الاجتماعي عذ الأطفال من وجهة نظر الأهالي ـشه إبراهيم المفلح 
الألعاب الإكترونية وعلاقتها بالنمو الاجتماعي عند الأطفال من وجهة نظر

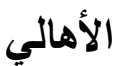

أ.شهد إبر اهيم المفلح ـ. هانيا منير الشنواني

DOI : $10.12816 / 0053078$

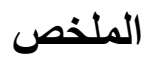

تهدف هذه الدراسة إلى معرفة علاقة الألعاب الإلكترونية و النمو الاجتماعي عند

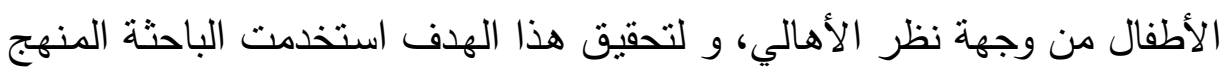

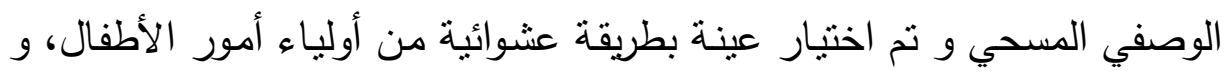

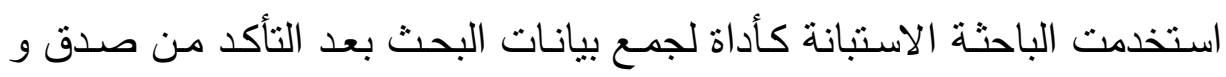
ثبات الأداء وقد كثف البحث عن النتائج التالية: اتفق أولياء الأمور على عدد باته من الإيجابيات، أهمها أن الألعاب الإلكترونية تساعد على تتمية مهارات استخدام

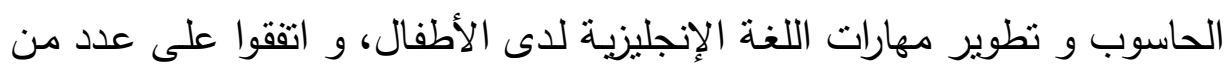

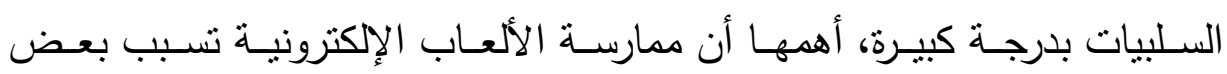

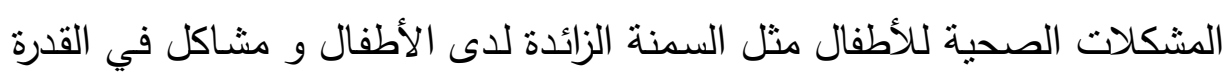

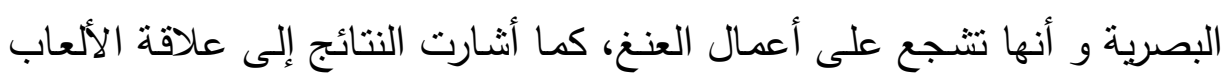

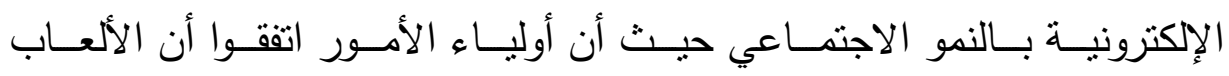

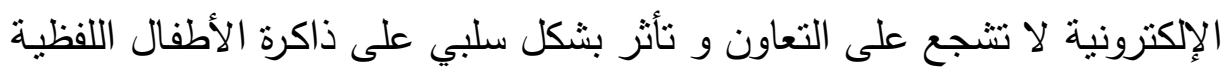
و تسبب الهروب من الجلسات و الاجتماعات العائلية.

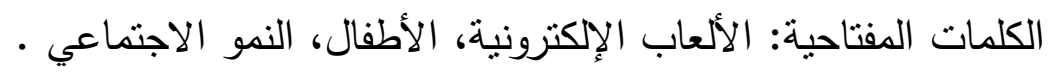




\begin{abstract}
The aim of this study is to identify the relationship between electronic games and children's social growth from the point of view of the parents. To achieve this goal, the researcher used the descriptive survey method. The sample was randomly selected from the parents of the children. The researcher used the questionnaire as a tool for collecting research data after confirming the validity and stability of performance. The research has revealed the following results: Parents agreed on a number of advantages, the most important of which is that electronic games help to develop the skills of children's computer use and the development of English skills, and agreed on a number of disadvantages to a large extent, That the exercise of electronic games cause some of children's health problems, such as children's obesity and problems of visual capacity and it encourages violence, and the results indicated the relationship of electronic games with social growth as parents agreed that electronic games do not encourage Cooperation and negatively affected children's verbal memory and caused the escape of meetings and family meetings.
\end{abstract}

Keywords: electronic games, children, social growth. 
أصـبحت ثورة الاتصـالات، والعولمــة ظـاهرتين متلازمتين لا بمكن أن نتفصـل

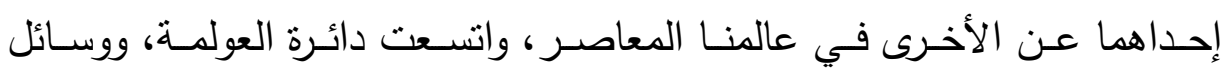
الاتصال المختلفة التي قربت المسافات والاتصالات بين الجميع.( أحمد، 2017)

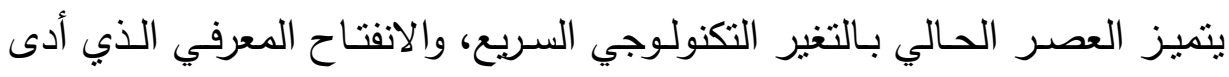

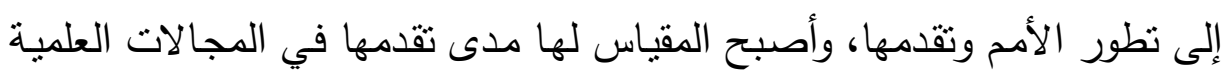

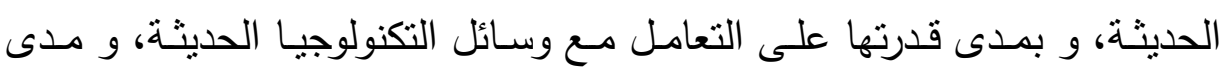

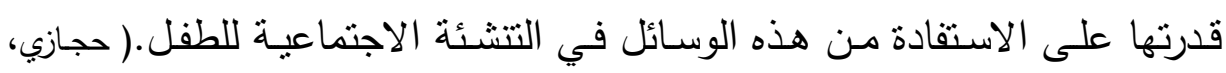
(2010

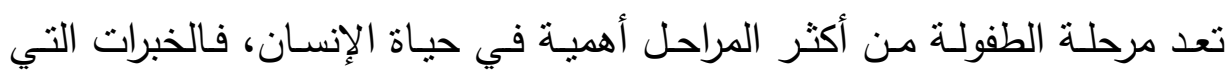
ينلقاها الطفل في سنواته الأولى توفر الأساس الذي تبنى عليه تكويناته المختلفة،

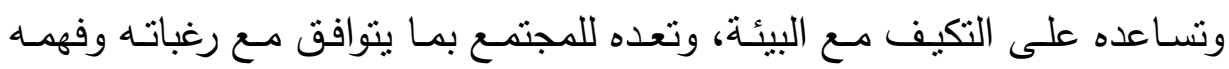
لذاته. (القحطاني، 2017) حيث أشـار الصوالحة( 2016) إلى أن أكثر الألعاب شيوعا في هذا العصر مـا ألهاب

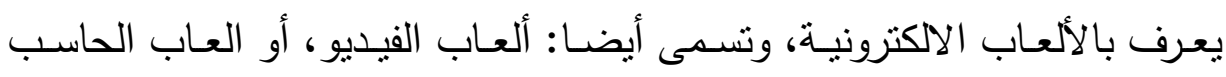

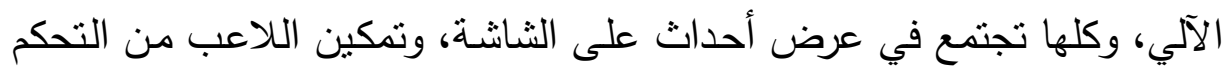
في مجريات هذه الأحداث فيما يعرف بالعلاقة التفاعلية.

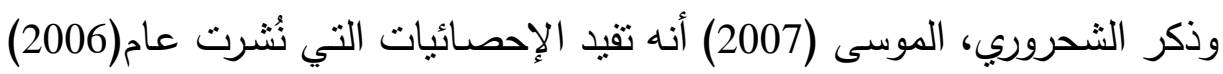

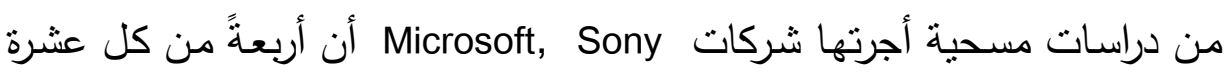

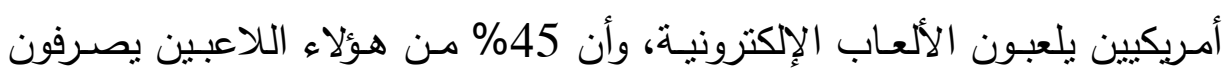

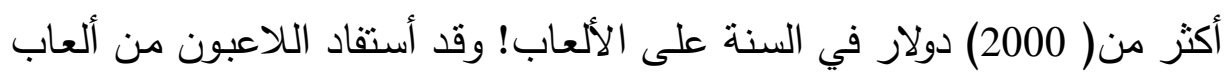
الإنترنت بأنهم كونوا صداقات وعلاقات مع لاعبين آخرين لم يعرفوهم من قبل.

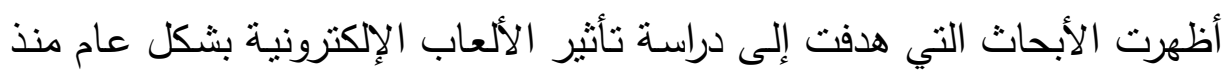

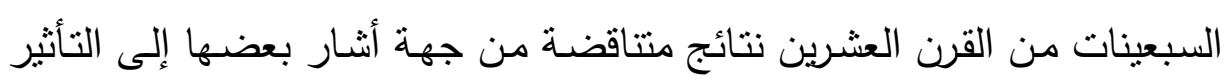


السلبي للألعاب الإلكترونية خاصـة في زيادة العدوان، ومن جهة أخرى وضحت

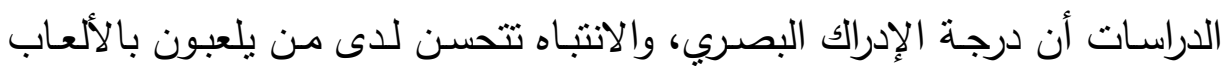
الالكترونية.( المعوض، الموسى، 2016) ولكن قد يكون استخدام الأطفال المفرط للألعاب الإلكترونية سبيا في الحد من

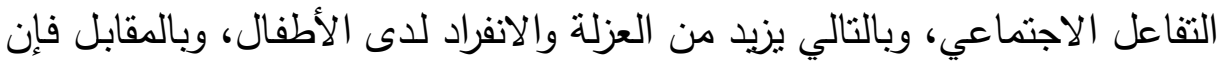

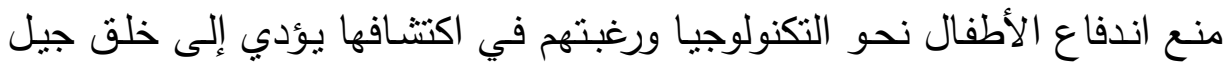
غير مواكب للتقافة الإلكترونية المتزايدة. (الفردان، 2012) وبالنظر للانتشار الواسع اليوم للألعاب الإلكترونية عند الأطفال، وماله من آثنار

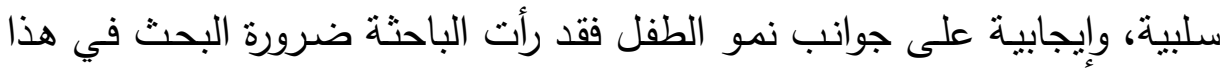

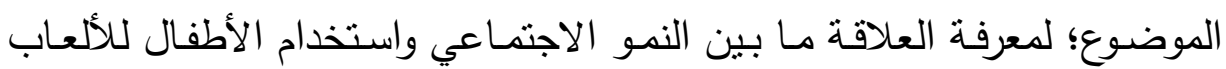
الإلكترونيـة، والآثار السـلبية المترتبـة عليهـا، ومـا إذا كانـت هنـاك آثنار إيجابيـة يمكننا النظر إليها عند استخدام الأطفال لهذه الألعاب.

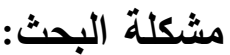
تكسب الدراسة الحالية مشكلتها عندما كشفت عدد من الدراسات عن الصعوبات الاجتماعية التي يعاني منها الأطفال الذين يمارسون الألعاب الإلكترونية لساعات

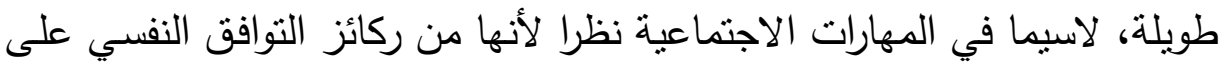

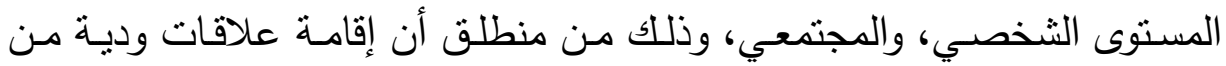
بين المؤشرات الهامة للكفاءة في العلاقات الثخصية للطفل. ( ميهوب، 2013) وتظهر مشكلة الدراسـة في السؤال الرئيسي التالي: مـا علاقـة استخدام الأطفال للألعاب الإلكترونية على نموهم الاجتماعي؟

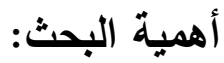
تكمن أهمية الدراسـة من جانبين رئيسيين هما الجانب النظري والجانب العملي 
الجانب النظري: تقصـي علاقة استخدام الأطفال للألعـاب الإكترونيـة، ونموهم

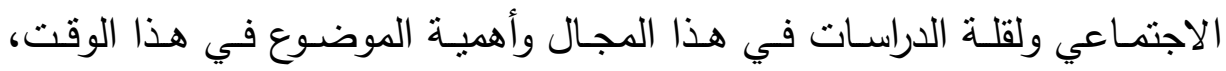
وتقديم إضافة علمية للمكتبة العربية.

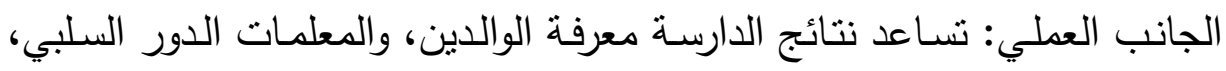
والإيجابي الذي تقدمه هذه الألعاب، وكيف يمكن استقادة أطفالهم منها وابتعادهم عن أخطارها.

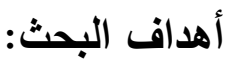
يهدف البحث الحالي إلى: 1-التعرف على الدور الإيجابي الذي تقدمه الألعاب الإلكترونية للأطفال. 2-التعرف على الدور السلبي الذي تقدمه الألعاب الإلكترونية للأطفال.

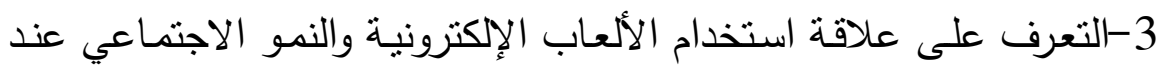
الأطفال.

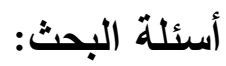

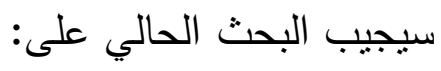
-1ما الدور الإيجابي الذي تقدمه الألعاب الإكترونية للأطفال؟ -2ما الدور السلبي الذي تقدمه الألعاب الإلكترونية للأطفال؟ -3ما العلاقة بين استخدام الألعاب الإلكترونية والنمو الاجتماعي عند الأطفال؟ حدود البحث: الحدود الموضوعية:

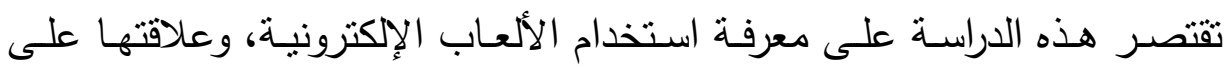
النمو الاجتماعي لدى الأطفال والمقصود بالألعاب الإلكترونيـة في هذ البحثب:

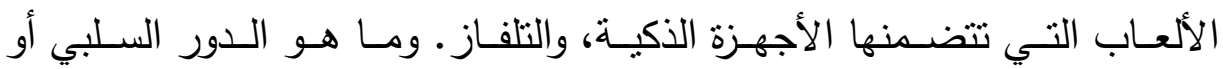
الإيجابي الذي تقدمه هذه الألعاب على الأطفال. 


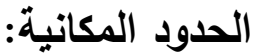

أمهات وآباء الأطفال في مدينة الرياض.

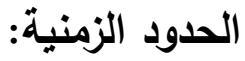

تم تطبيق إجراءات هذه الدراسـة خـلال العام الدراسي الثناني من العام 1438-

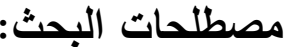

الألعـاب الإلكترونيـة:" نشـاط منظم يتت اختيـاره وتوظيفهـ لتحقيـق أهداف محددة

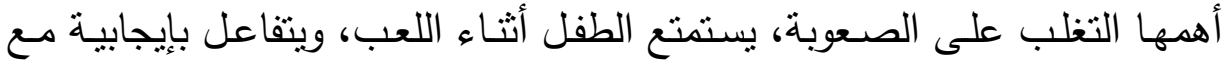
الكمبيوتر ، ويمارس التفكير واتخاذ القرار السريع بنفسه ويتعلم الصبر ، والمثابرة أو

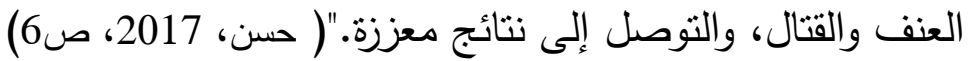

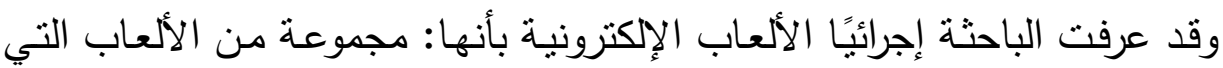

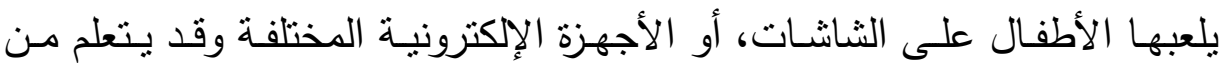
خلالها الطفل ما هو سلبي أو ايجابي. الطفولـة المبكرة: "هـي مرحلـة تكوينيـة للفـرد يـتم فيهـا نمـوه الجســي، والعقلِي

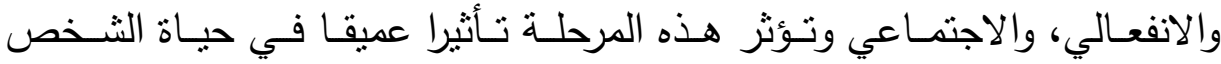

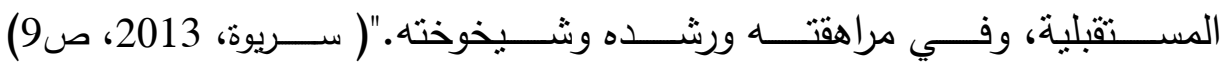

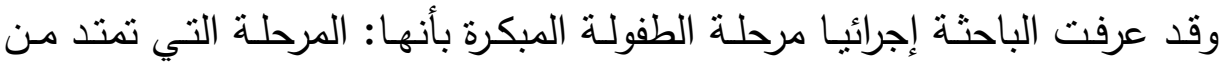

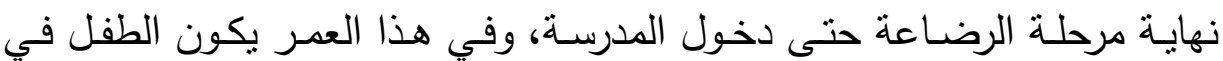

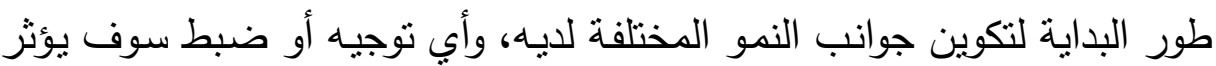
على الطفل إيجابيا، أو سلبيا في مراحل حياته المقبلة. النمو الاجتماعي: "هو تلك التغيرات التي يمر بها الطفل، والتي ترتبط بالعلاقات الاجتماعية والعادات والتقاليد ويظهر النمو الاجتماعي للطفل من خـل سلوكه

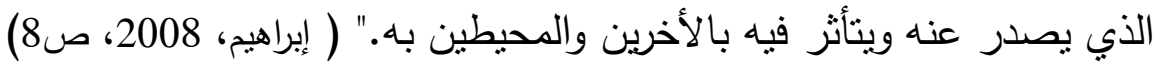


وقد عرفت الباحثة إجرائيًا النمـو الاجتمـاعي أنها: حسن التصـرف في المواقف

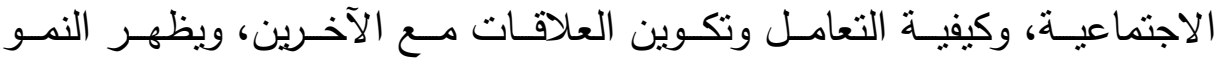

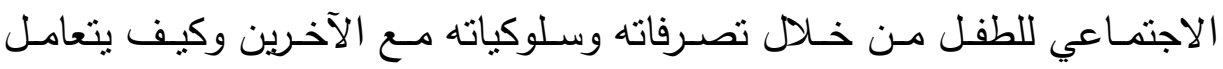
الطفل مع الأشخاص المحيطين به. التمهيد: يعد اللعب أساسـا لا غنى عنه في حياة الطفل، فهو عـالمٌ خيالي يعيش فيه،

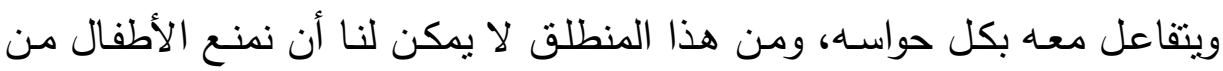

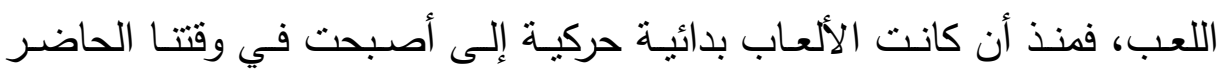
ألعابا إلكترونية متتوعة كان ومازال دورها كبيرًا في نمو شخصية الطفل، واندماجهـ

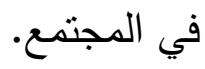

\section{اللعب في الطقولة المبكرة:}

"عرف تايلور اللعب أنه: هو أنفاس الحياة بالنسبة للطفل إنه حياته، و ليس مجرد طريقة لتمضية الوقت و إنشغال الذات، فاللعب للطفل هو كمال للتربية، و

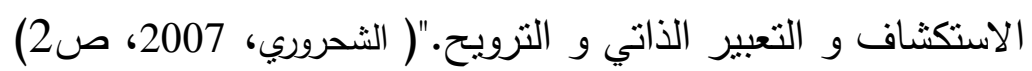
وإن أهم حاجات الطفل هي الأكل، واللعب والنوم ولعل اللعب في الطفولة وسيط النديط

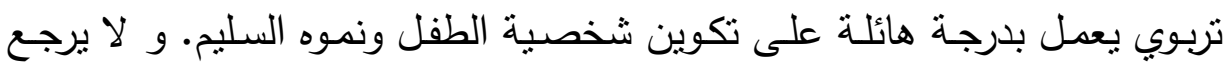
مصدر هذه الأهمية إلى أن الطفل يقضي جل وقته في اللعب بعيداً عن الحياة

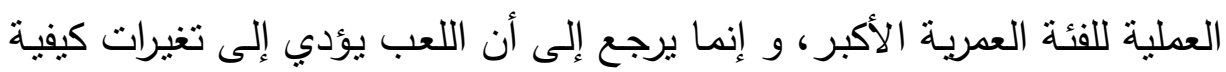

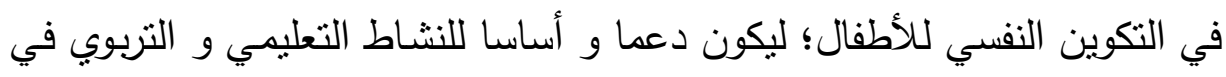

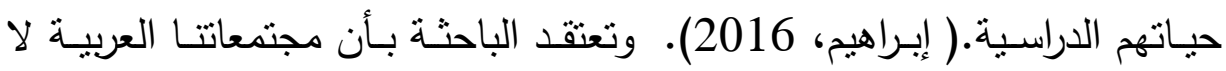
تتظر إلى اللعب لدى الأطفال بأنه يؤثز في نمو شخصياتهم و يجعل منها أكثر

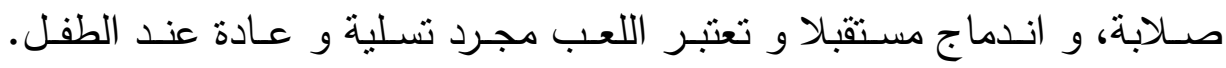
$:$

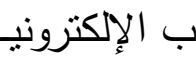
الألع

بين الثـحروري( 2007) في بدايـة الثمانينـات و مـع التطور التكنلوجي، بـرزت 189 
أثـكال للألعـاب لـم تكـن معروفـة مـن قبـل، و أصبــت دورا أساسـيا في ثقافـة (Electronic Games). الأطفال سميت هذه الألعاب بالألعاب الإلكترونية

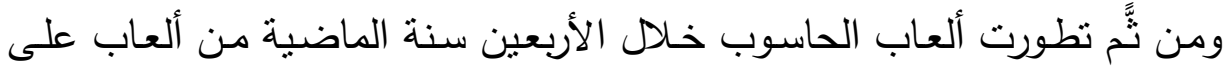
الأشرطة المرنة إلى القرص المدمج إلى شبكة الإنترنت.

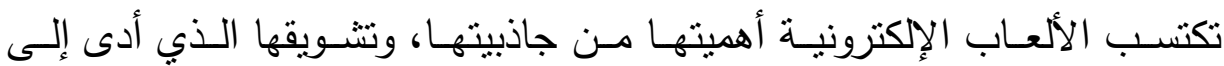

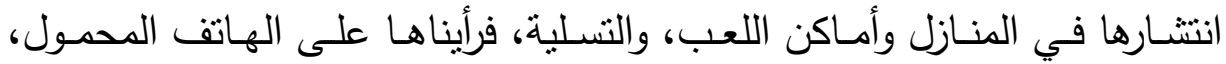
وجهاز الحاسوب وغيرها، وتعد الألعاب الإككترونية الأجنبية الأكثر إنتاجا وانتشارا مقارنة مع الألعاب الإلكترونية في الوطن العربي. ( إبراهيم، 2016) وترى الباحثة أنه من الواجب علينا تشجيع إنتاج الألعاب الإلكترونية العربية لكي تتتاسب مع عاداتتا وتقاليدنا الإسلامية، وتحمل الهوية العربية لا الهوية الأجنبية. ترى إبراهيم( 2016) بأن الألعاب الإلكترونية تعد أحد أكثر وسائل التزفيه انتشاراً

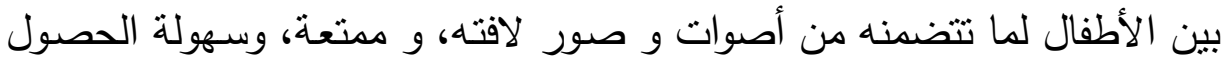
عليها من خلال شبكة الإنترنت أو شرائها بأسعار رمزية. فالألعاب الإككترونية هي ألعاب مبرمجة تسمى ألعاب الديجيتال (الألعاب الرقمية)

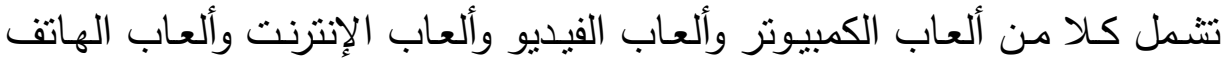
النقال.( حجازي، 2010) آثار الألعاب الإكترونية الإيجابية والسلبية: في خضم هذا الاهتمام الكبير بالألعاب الالكترونية ينساءل المرءء عن الآثار التي الإبه

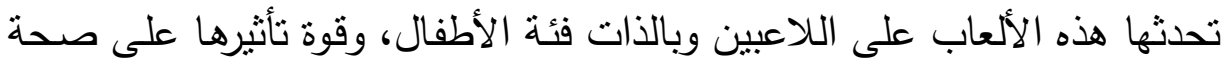
الطفل، وقيمه وسلوكه ولغته وشخصيته بشكل عام، كما أن لها سلبيات، فإنها لا تخلو من الإيجابيات، فقد أجريت العديد من البحوث والدراسات التي تتاولت تأثثر ونير

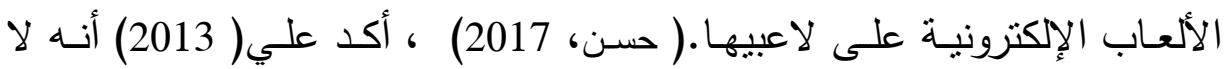
يمكن أن ننكر إيجابيات بعض الألعاب الإلكترونية الحديثة كتعليم اللغة العربية،

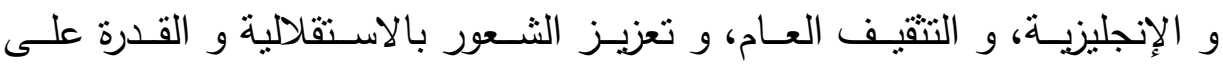


الإنجاز على المستوى الفردي، و كذلك تعليم الطفل دقة الملاحظة، وزيادة قدرته على التركيز ، و الاستغراق في اللعب بشكل كبير.

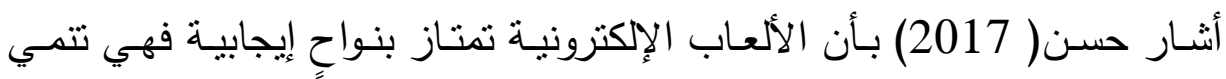
الذاكرة، و سرعة التفكير، كما تطور حس المبادرة و التخطيط و المنطق، و مثل هذا النوع من الألعاب يسهم في التآلف مـع التقنيات الجديدة ليكون الطفل مواكبا

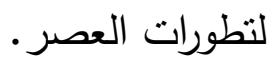
إن اسـتخدام ألعـاب الحاسـوب للأطفـال كانـت تمثنل البدايـة الأولـى لاتصــالهم

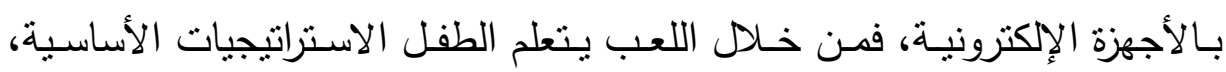

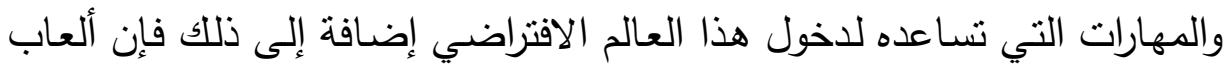

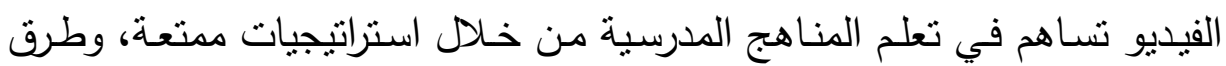
فاعلة.( الفردان، 2012) أكد مجموعة من الباحثين على إيجابية اللعب الإلكتروني ودوره الفعال في التعلم،

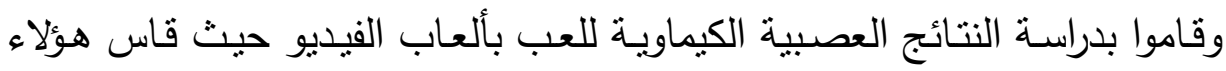
الباحثون كمية الدوبامين التي تفرز عند لعب الأطفال لعبـة الفيديو، (الدوبامين هو أحد الكيماويات في الدماغ يطلق عليه الناقلات العصبية التي نسمح بانتقال

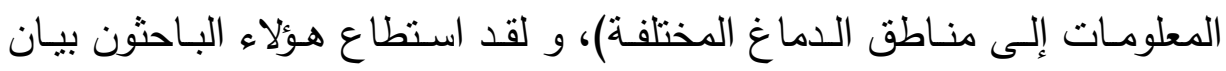
إفراز الدومابين في الفرد أثتاء لعبـه مما يؤدي إلى سرعة انتشـار التعلم بشكل هوله لبهل

$$
\text { أكبر · ( الفدران، 2012) }
$$

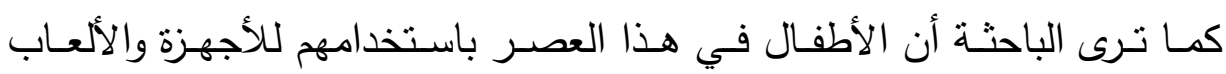
الإلكترونية جعلتهم أكثر قدرة على أخذ المعلومات، وترتيبها بشكل منظم بالطريقة

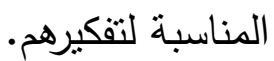
كما أن هنالك بعض الدراسات التي تؤكد وجود آثار ايجابية للألعاب الإلكترونية على سلوك الأطفال، وتحصيلهم الدراسي، أيضا هناك دراسات أخرى تبين الآثار

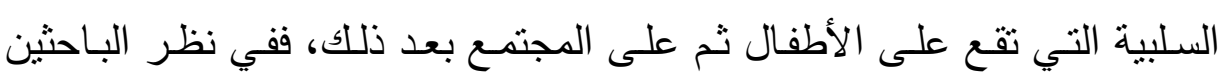


تتسـم بعض الألعـاب الالكترونيـة بـالعنف، وتتـاقض السـوك الاجتمـاعي السـوي المنضبط للطفل.( أحمد، 2016) وقد صنفت الآثار السلبية في الألعاب الإلكترونية كتالي:

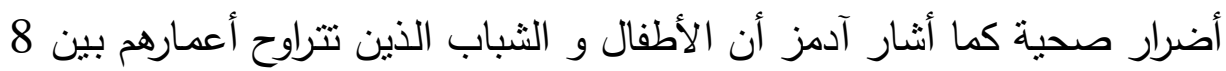

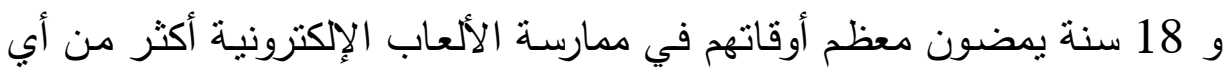

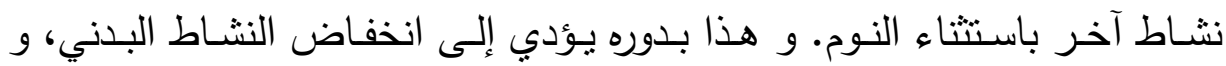

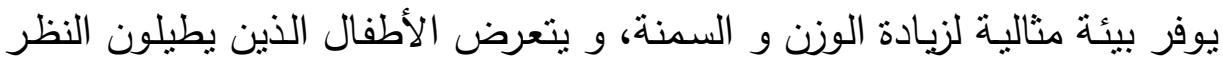

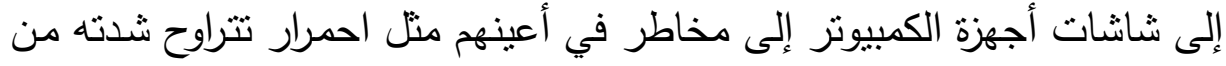

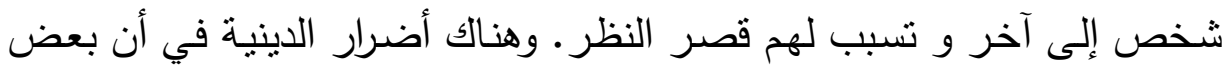
محتويات ومضـامين الألعاب الإلكترونيـة تحمل سلبيات، وطقوس دينيـة معاديـة

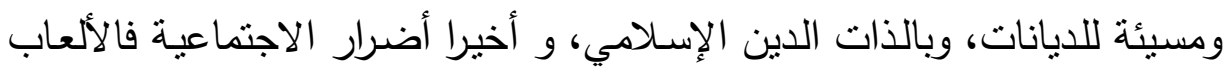

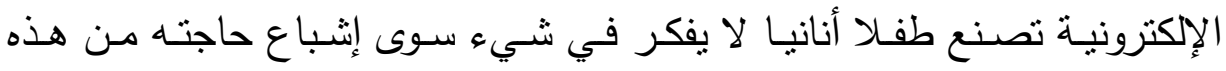
اللعبة.( محمد، 2013؛ حسن، 2017) ترى الباحثة أن الألعـاب الإكترونيـة أصبحت ضـرورةً لا يمكن الاستغناء عنهـا

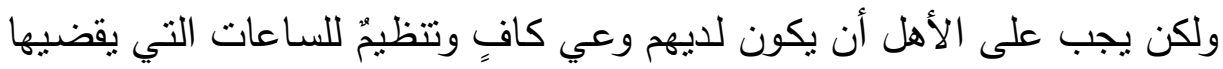
أبناؤهم على هذه الألعاب وانتقاء لنوعية الألعاب المناسبة للطفل وميوله. النمو الاجتماعي في الطفولة المبكرة: يقصد بالنمو عملية تغيير وتوجيه في مختلف النواحي الجسمية والعقلية والنفسية والاجتماعيـة، واللغويـة، ويرى (بياجيـه) أن النمو سلسـلة من الحلقات إذ تعد كل مرحلة امتدادا للمرحلة السابقة، وتمهيدا للمرحلة التالية.(ششتاوي و العجم، 2005) فالنمو الاجتماعي يكسب الطفل الاتجاهات الاجتماعية، والقيم والمبادئ، فتتسع ولئح دائرة علاقته وتفاعله الاجتماعي في أسـرته ومـع جماعـة رفاقهـ فتزداد، أهميتها ابتداء من العام الثالث، حيث يتمكن الطفل من مصادقة الآخرين واللعب معهم التهم

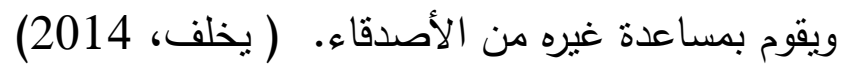

Doi : $10.12816 / 0053078$ 


\section{مظاهر النمو الاجتماعي في الطقولة المبكرة:}

ذكر أبو جادو (2015) أنه من أهم مظاهر النمو الاجتماعي في مرحلة الطفولة الطماعلة

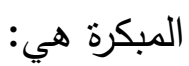

يظهر في لعب الطفل تطورا اجتماعيا واضحا حيث يميل الأطفال إلى تكوين جماعات صغيرة، وعلى الرغم من ذلك تكثر المشاجرات بين الأطفال لعدم قدرتهم

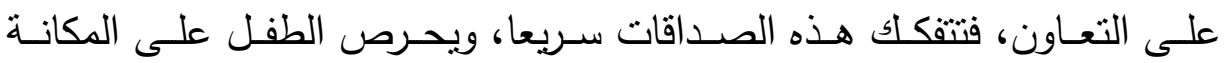

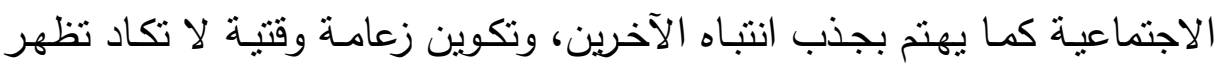

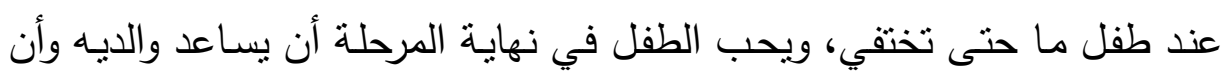
يساعد الآخرين.

تـرى الباحثـة أن نظريـة التعلم الاجتمـاعي هـي النظريـة الأنسـب لدراسـة تـأثنر

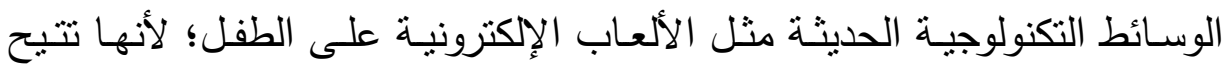
للفرد أن يشارك في عملية التعلم بواسطة تزويده بمناخ للتفاعل غير المباشر .

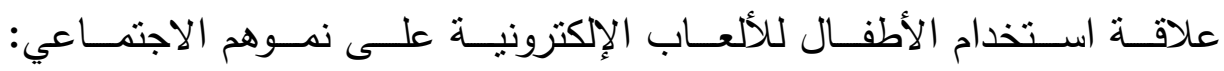
من خـلال عدد الساعات التي يقضيها الأطفال في ألعاب الكمبيوتر يبدأ الطفل بفقدان التواصل الاجتماعي، مع الأصدقاء وأطفال العائلة، وكذللك الثعور بالعزلة لهابلة

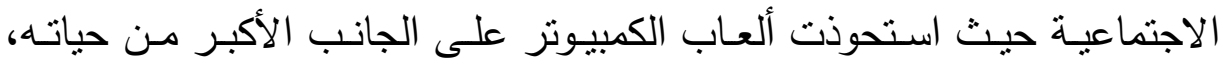
ومنعته من القيام بمهاراته الاجتماعية المختلفة. ( الفدران، 2012)

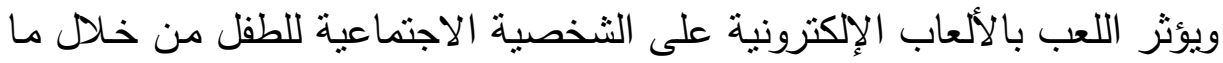

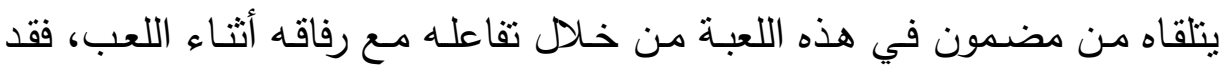

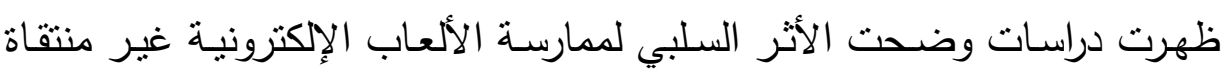

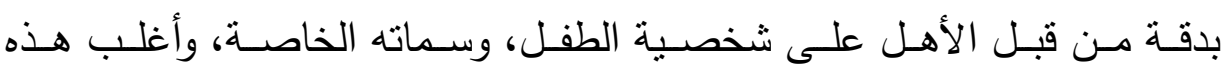

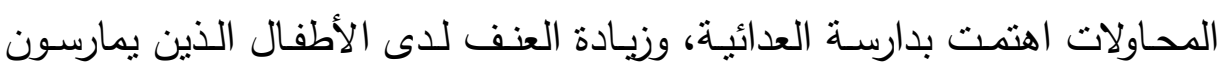
اللعب الالكتروني العنيف.( حجازي، 2010) 
وترى الباحثة أن الألعاب الإلكترونية أدت إلى عزلـة الأطفال التامـة عن أسرهم، ومجتمعه وخلق جسرا من عدم التوافق، والتقاهم فيما بينهم فأصبح العبء كبيرا

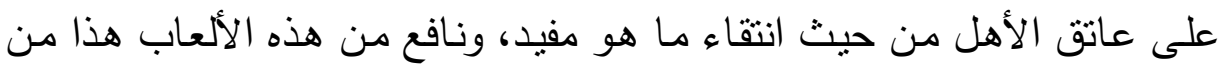

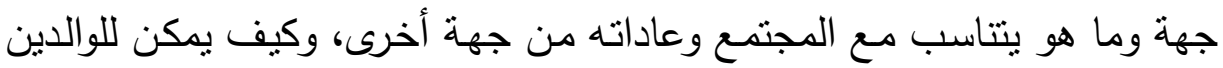

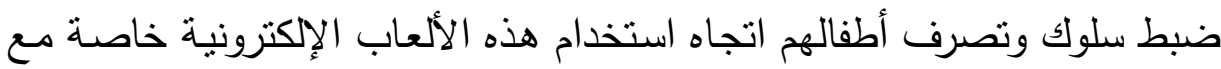
التقدم والتطور الهائل للتقنية.

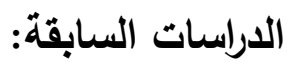

في هذا الجزء من الدراسـة قامت الباحثة بالبحث والاطـلاع على الدراسـات ذات

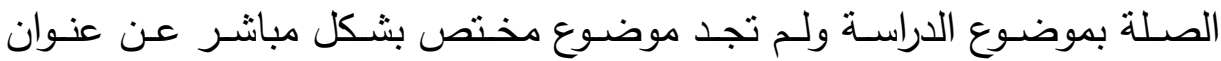
البحث وهو علاقة الألعاب الإككترونية بالنمو الاجتماعي عند الطفل، لكن وجدت بعض الدراسـات ذات الصـلة التـي تتاولت متغيرات الدراسـة، وقد توصـلت إلى الدراسات السابقة الاتية مرتبة وفق حداثتها بالنشر: ونم تقسيمها إلى محورين رئيسين: المحور الأول: دراسات تتاولت جانب الألعاب الإلكترونية:

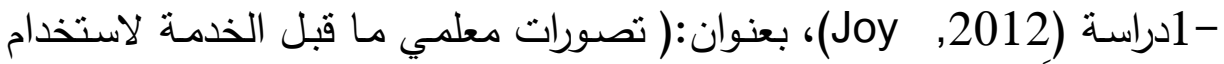
ألعاب الفيديو كأدوات تعليمية) تهدف الدراسة للتحقيق في تصورات "معلمي ما قبل الخدمة" عند استخدام ألعاب

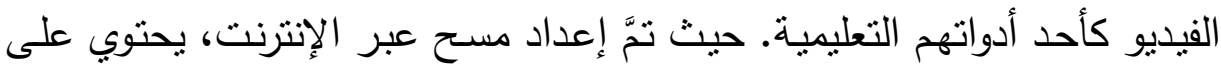

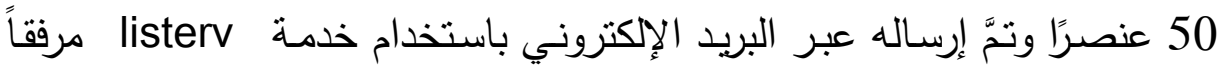
بورقة معلومات ورسالةٍ توضيحيةٍ مفصَّلةٍِة توضِّحُ بروتوكول البحث. وقد أنثارت

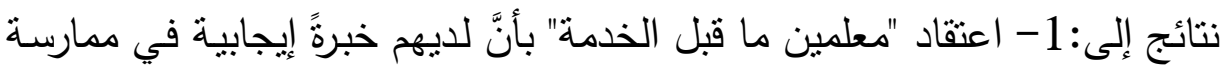

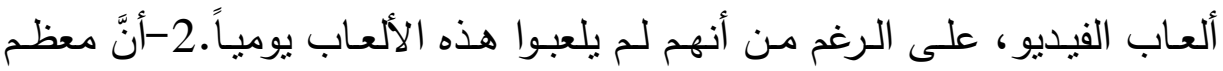

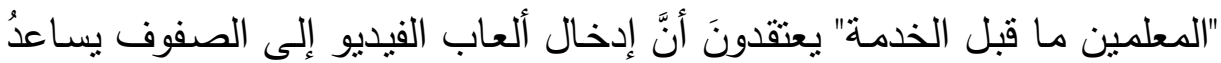

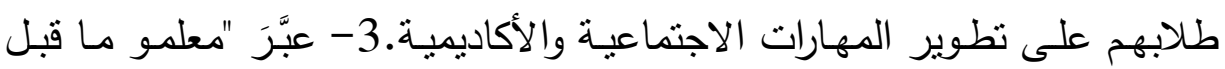


الخدمة" عن ارتياحهم لدمج ألعاب الفيديو في مناهجهم بمساعدة مديري المدارس

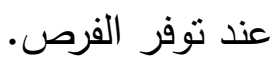
-2دراسة(إبراهيم، 2016)، بعنوان :( إيجابيات الألعاب الإلكترونية التي يمارسها

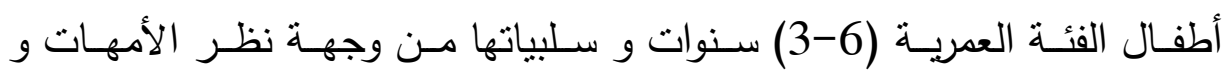

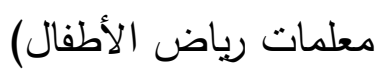
تهدف الدراسـة إلى استقصـاء إيجابيات الألعاب الإلكترونيـة التي مارسها أطفال

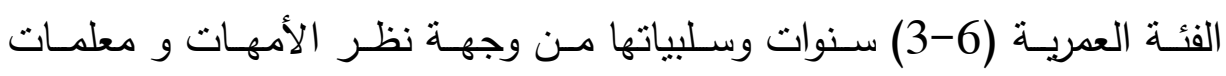

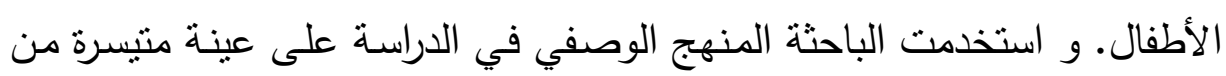

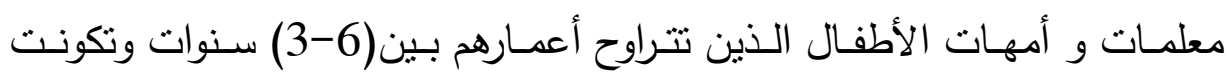

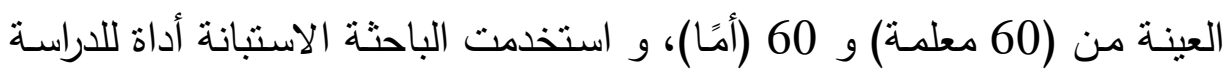

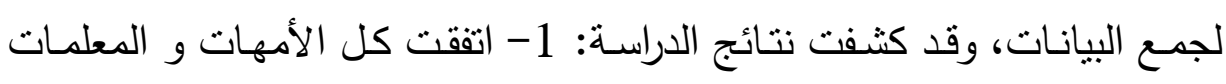
على عدد من الإيجابيات و بدرجة كبيرة و أهمها: انها نسهم في تحفيز الخيال للدى الأطفال، و تساعد على تعلم اللغـة الإنجليزيـة، وسيلة ترفيـه تعليميـة ذاتيـة.

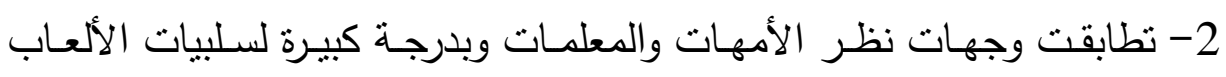
الإلكترونية وأهمها: ادمان الأطفال على هذا النوع من الألعاب، تأثثرها السلبي

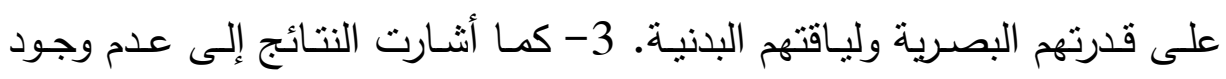
فروق ذات دلالة إحصائية في تقديرات أفراد العينـة لإيجابيات وسلبيات الألعاب الئل الإلكترونية.

-3دراسة(حمدان، 2016)، بعنوان: ( إيجابيات الألعاب الإكترونية التي يمارسها

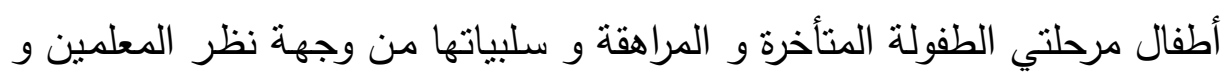
الأطفال أنفسهم)

وهدفت الدراسة إلى استقصـاء إيجاييات الألعاب الإلكترونية التي يمارسها أطفال

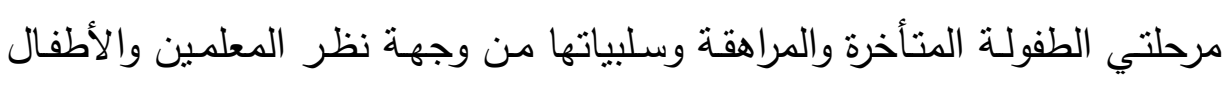

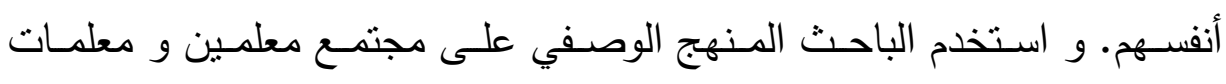
195 
الطفولة المتأخرة و المراهقة بالمدارس الخاصة التابعة لوزارة التربية و التعليم لواء

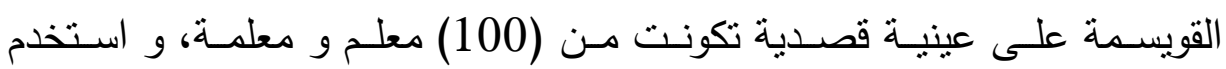

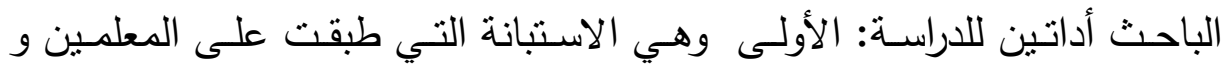

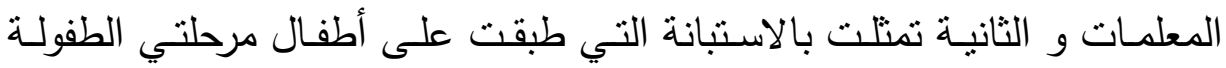

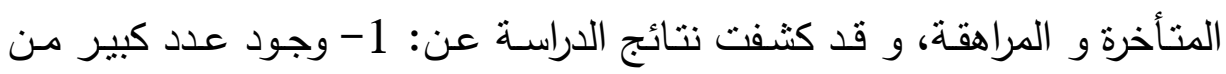
الإيجابيات الناتجة عن ممارسة الألعاب الإلكترونية و من ابرزها أنها تعمل على ولى الته تقويـة التآزر البصري/ الحركي لديهم. وتعودهم على الدقة في العمل. كمـا أنها

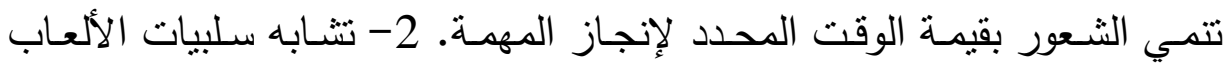

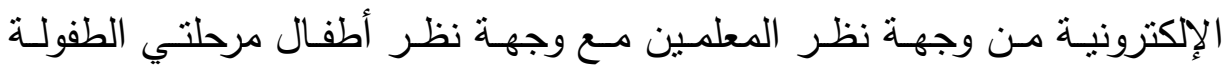
المتأخرة والمراهقة. 3-وجود فروق ذات دلالة إحصائية في تقديرات أفراد العينة

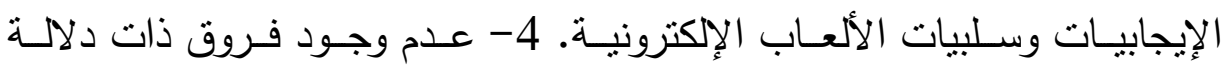
إحصـائية لسلبيات الألعاب الإككترونيـة مـن وجهة نظر أطفال مرحلتي الطفولـة الإنة

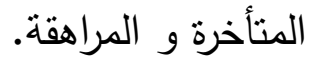
-4دراسـة(النيف، 2017)، بعنوان: (الألعاب الإلكترونيـة و تداعياتها على القيم التربوية لدى طلاب المرحلة المتوسطة: دراسة ميدانية)

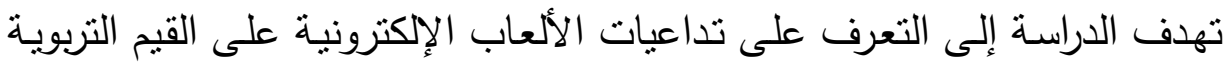

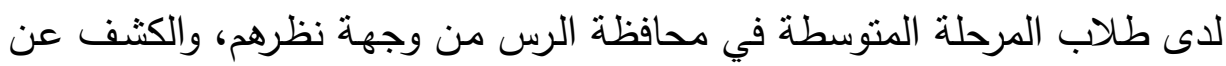
الفروق حول تداعيات الألعاب الالكترونية على القيم التربوية لدى طلاب المرحلة

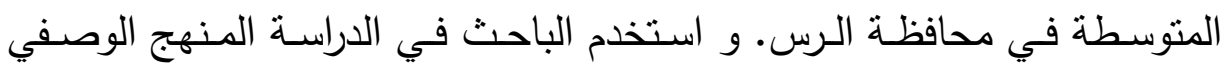

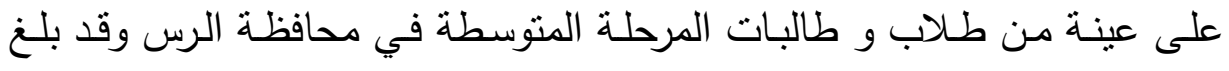
عددها (758) طالبـا و طالبـة و تـم اختيـارهم بطريقـة الطبقيـة العشـوائية ، وقد

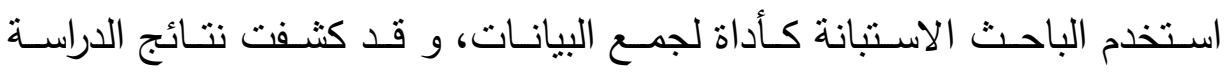

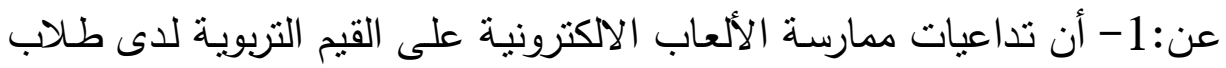

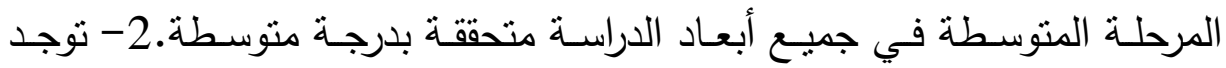


فـروق فـي اسـتجابات أفـراد عينــة الدراســة حـول تــداعيات ممارســة الألعـاب الالكترونية على القيم التربوية، راجعة لاختلاف الصف الدراسي.3-لاتوجد فروق

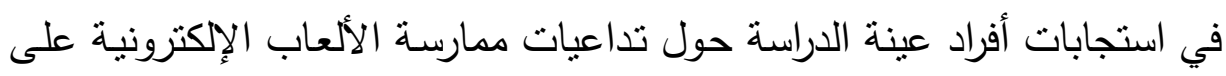
القيم التربوية، راجعة لاختلاف الصف الدراسي.4- توجد فروق دالة إحصائيا في

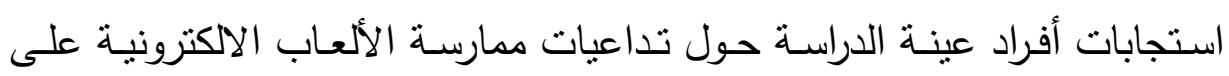

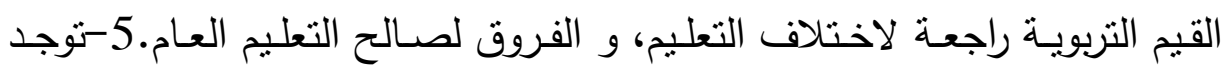

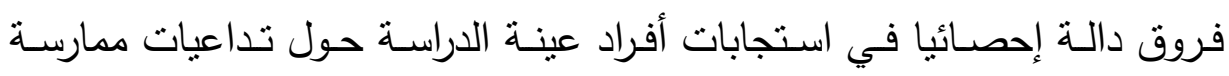

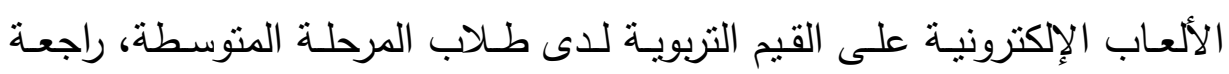

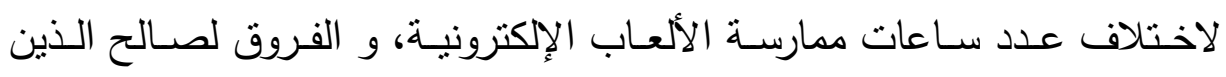
يمارسون الألعاب الإكترونية لعدد ساعات من ساعة لأقل من ساعتين. المحور الثاني: دراسات تتاولت جانب النمو الاجتماعي:

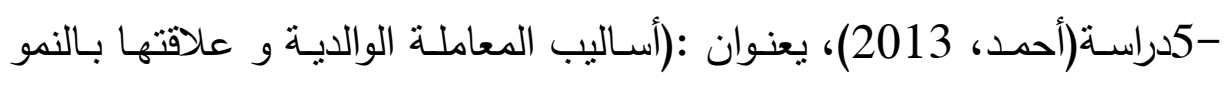

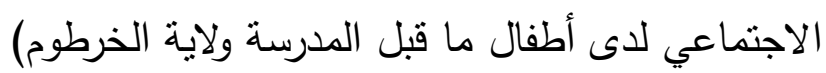

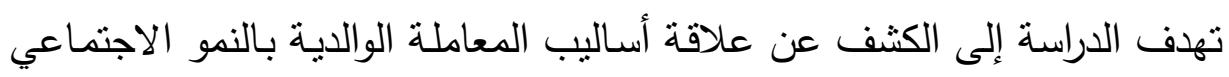

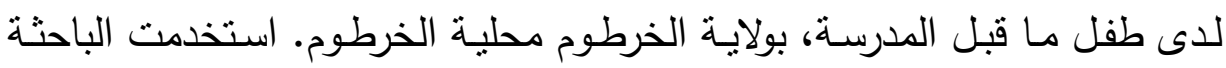

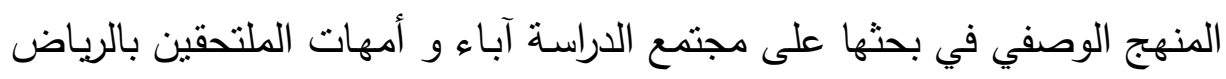

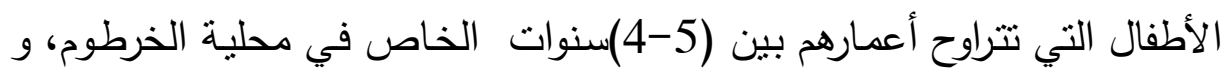

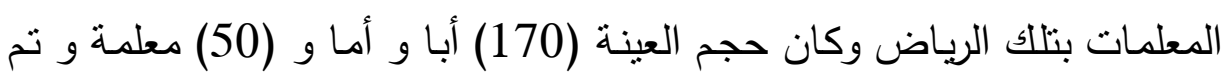

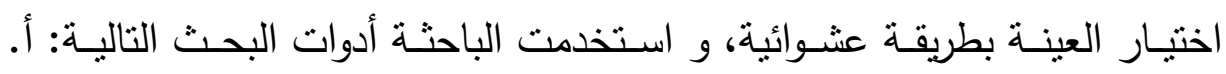

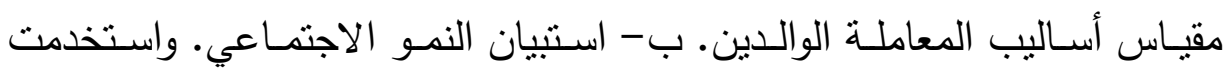
الباحثة في المعالجات الإحصائية برنـامج(spss) ، وتوصلت إلى أهم النتائج

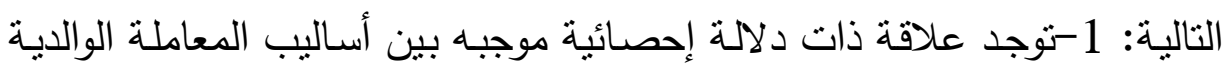

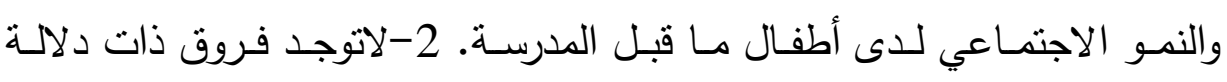


إحصائية في أساليب المعاملة الوالدية تبعا لاختلاف نوع الأبن(ذكر، انتى). 3لا توجد مشكلات في النمو الاجتماعي لاى أطفال ما قبل المدرسة.

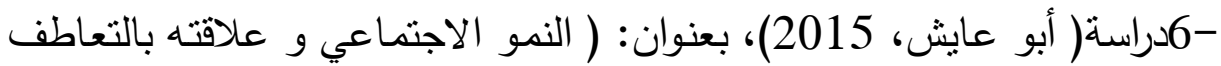
النفسي لدى طلبة المرحلة الثانوية في قضاء بئر السبع) تهدف الدراسة إلى التعرف على النمو الاجتماعي وعلاقته بالتعاطف النفسي لدى طلبة المرحلة الثنانويـة في قضاء بئر السبع. و استخدم الباحث المنهج الوصفي

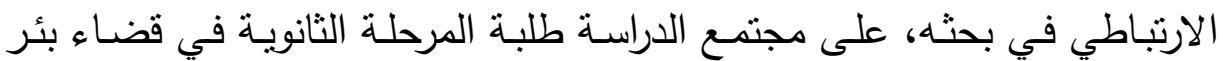
السبع على عينة تكونت من (293) طالبا و طالبة من طلبة المرحلة الثانية في قضـاء بئر السبع و تم اختيارهم بطريقة الطبقيـة العشوائية، و استخدم الباحث أدوات البحث التالية: مقياس النمو الاجتمـاعي، و مقياس التعاطف النفسي بعد التهد

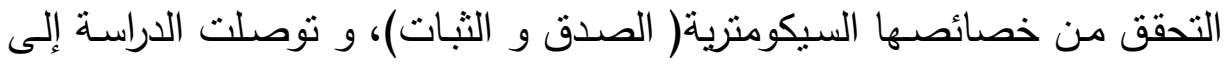

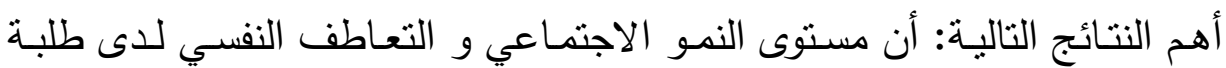
المرحلـة الثانويـة كان مرتفعـا. 2- وجود فروق دالـة إحصـائيا في مستوى النمو

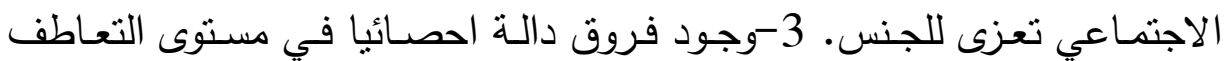
النفسي تعزى للجنس. 4-عدم وجود فروق دالة إحصائيا في مستوى التعاطف النفسي تعزى للصف. 5- ووجود علاقة ارتباطية إيجابية دالة احصائيا بين النمو الاجتماعي ككل وجميع ابعاده والتعاطف النفسي ككل وجميع ابعاده. تعقيب على الدراسات السابقة: لعل من أهم الدراسـات التي استقدت منها دراسـة أحمد(2012) و دراسـة إبراهيم (2016) فهي تنتابه مع عينـة دراستي وهم الوالدين، وفي دراسة أحمد (2012) و دراسة إبراهيم (2016) كانت دراستهم مختصه في مرحلة رياض الأطفال وهذه دها المرحلة التي يستهفهها البحث الحالي، و في جميع الدراسات استخدم الباحثون في

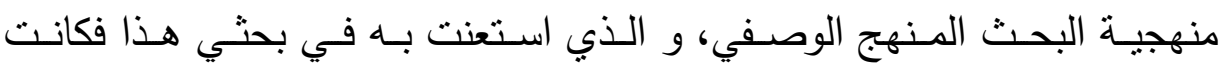
انطلاقتي من الدراسات السابقة، و التي أفادت في تحديد اختيار العينية، والمنهج 
و أداة و بناء الاستبانة على أسس صحيحة، فتم الاستعانة بدارسة أحمد(2012)

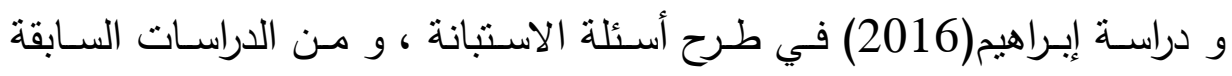

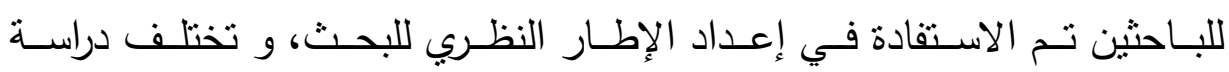

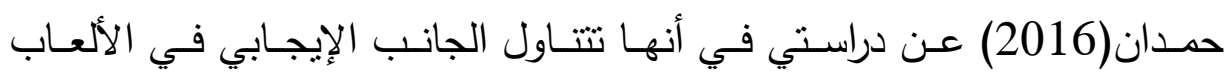
الالكترونية فقط وذلك في مرحلتي الطفولة المتأخرة و المراهقة، واختلفت أيضـا

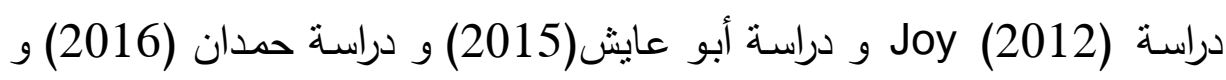
دراسة النيف (2017) عن دراستي في مجتمع الدراسة.

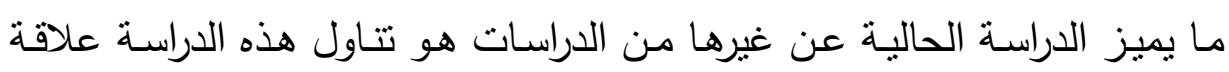

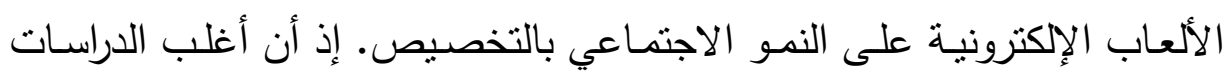

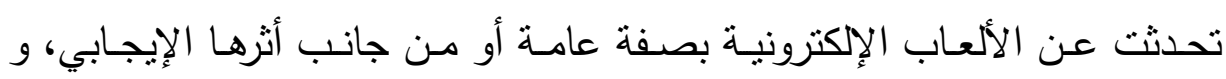

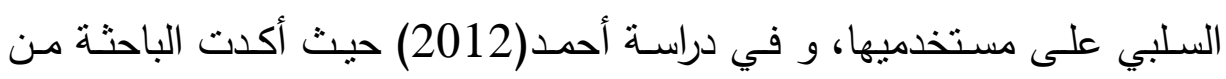

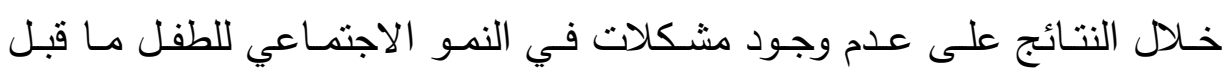

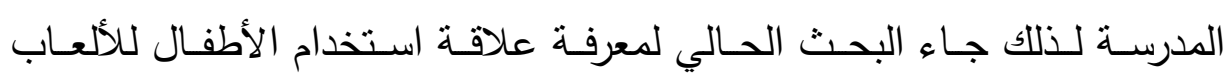
الإكترونية في نموهم الاجتماعي و ما تحدثه من مشاكل للطفل.

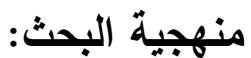

انطلاقا من طبيعة الدراسـة التي تهدف لمعرفة علاقة استخدام الأطفال للألعاب

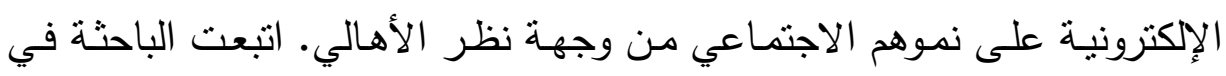
هذا البحث المنهج الوصفي المسحي، والذي يعتمد على دراسة الواقع أو الظاهرة كما هي في الواقع، ويهتم بوصفها وتوضيح خصائصها، والتعبير عنها تعبيراً

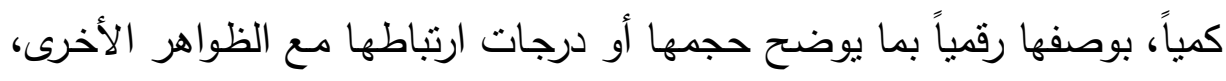

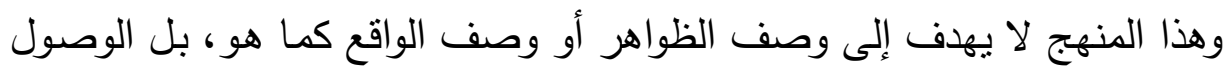
إلى استتناجات تسهم في فهم هذا الواقع وتطويره. مجتمع البحث: يتكون مجتمع الدراسة من أمهات وأباء الأطفال في مدينة الرياض. 


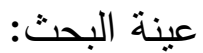

تم اختيـار العينـة بطربقة العينـة عشوائية، حيث يبلـغ إجمالي العينـة (40) ونسبة إلى محدوديـة مجتمع الدراسـة وبعد التطبيق الميداني حصلت الباحثة على (40) اسـتبانة صـالحة للتحليـل الإحصـائي وهي تعتبـر عينـة عشـوائية ممثلـة لمجتــع

أداة البحث:

بنـاءً على طبيعـة البيانـات التي يـراد جمعها اسـتخدمت الباحثة الاسـتبانة كـأداة لجمع البيانـات و لكونها الأداء المناسبة لجمـع البيانـات حسب المنهج المستخدم، وقد تـم بنـاء أداة البحـث بـالرجوع الـى الدراسـات السـابقة ذات العلاقـة بموضـوع البحـث و مـن هذه الدراسـات دراسـة أحمـد(2012) و دراسـة إبراهيم (2016) تم

تصميم الاستبانة وفقاً لأسلوب الأسئلة المغلقة (Closed Questionnaire) متعددة الاختيارات بحسب مقياس ليكرث الثلاثي (موافق، محايد غير موافق) ، و تكونت الأداءة مـن جزئين الجزء الأول تحتوي على معلومـات عن العينيـة في ضـوء المتغيـرات التاليـة( العمـر ، المسـتوى الاقتصــادي، حجـم الأسـرة) و الجـزء الثاني تكونت من المحاور الرئيسـة للدراسـة و كانت من محورين محور الألعاب الإلكترونيـة و تتكون مـن (10) فقرات و محور النمو الاجتمـاعي و تتكون مـن

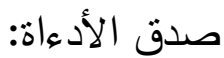
تم عرض الاستبانة بصورتيها المبدئية على عدد من المحكمين من ذوي الخبرة و الاختصـاص والمعرفـة والكفـاءة في مجـالات البحـث العلمسي لقيـاس الصـدق الظاهري في الأداء من خـلال توزيـع أداة الدراسـة (الاستبانة) وقد طلبت الباحثة من المحكمين إبداء آرائهم وملاحظاتهم حول مدى وضوح كل عبارة من عبارات محساور الاستبانة ومدى مناسـتتها لقباس مـا وضـعت لقياسـه؛ ومدى ملائمسة كل عبارة من العبارات للمحور الذي تتتمسي إلبه؛ فضـلاً عن إدخال أي تعديلات أو 
إضـافات على العبارات التي تحتاج إلى ذلك، أو حذف العبارات غير المناسبة منها، وتحديد مدى ملائمـة التدرج الذي يحدد استجابة أفراد عينـة الدراسـة لكل

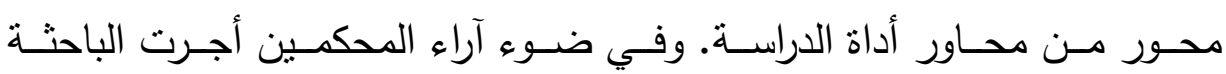
التعديلات التي اتفق عليها المحكمون بحذف وتعديل صباغة بعض العبارات؛

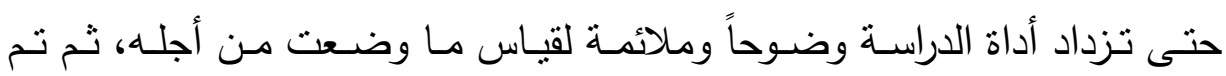
إخراجها بصورتها النهائية. ثنات الأداءة:

قامـت الباحثـة باسـتخدام ثبــات الأداعة بعـد التأكـد مـن الصـدق الظـاهري لأداة

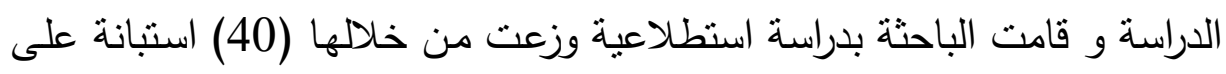

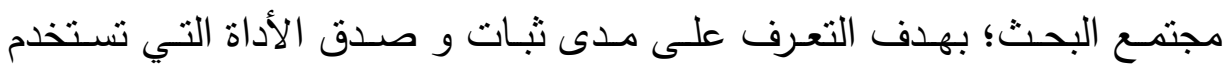

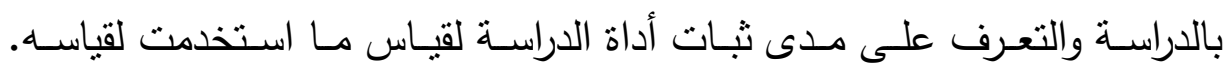
ولقيـاس مـدى ثبـات الدراسـة، اسـتخدمت الباحثـة (معامـل ألفـا كرونبـاخ ل (cronbach's Alphas )؛ للتأكد من ثبات أداة الدراسـة، حيث طبقت المعادلة على العينة الاستطلاعية لقياس صدق الاتساق الداخلي، حيث بلـغ معامل ثبات الأداء( 0.89)وهذه القيمة لمعامل ألفا كرونياخ مرتفعة؛ مما يؤكد ثبات الأداءة. اجراءات البحث: تم الاطـلاع على الادب النظري و الدراسـات السـابقة المتعلقة بموضـوع البحـث وبعد التأكد من الصدق الظاهري، ومعامل ثبات الدراسة (الاستبانة) قامت الباحثة الادئة

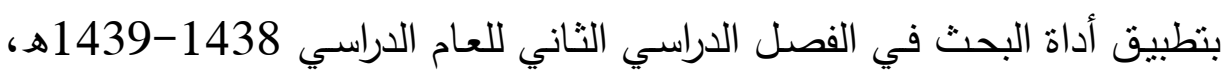

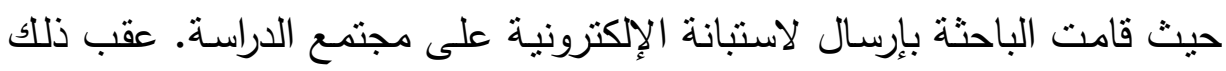

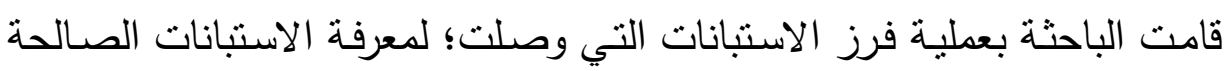

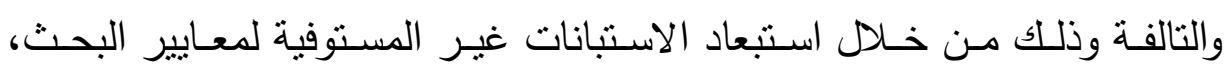

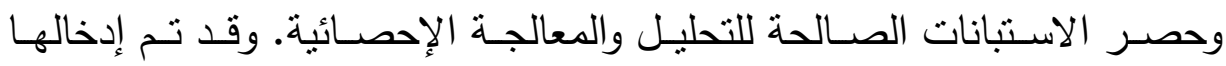
للحاسوب باستخدام برنامج SPSS بإعطائها أرقاماً معينة، أي بتحويل الإجابات 201 
اللفظيـة إلـى رقميـة (الترميزز) حيـث أعطيت الإجابـة لتحليـل البيانـات التي تم

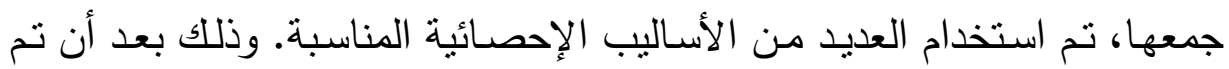
ترميز وإدخال البيانات على برنامج SPSS ، ولتحديد طول خلايا المقياس الثثلاثي (الحدود الدنيا والعليا ) المستخدم في محاور البحث ، تم حساب المدى( 3-1=2)، ثم تقسيمه على عدد خلايـا المقياس للحصـول على طول الخليـة

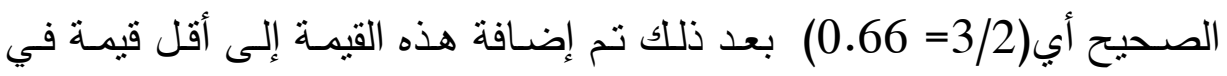
المقياس ( أو بداية المقياس وهي الواحد الصحيح) وذللك لتحديد الحد الأعلى لهذه الخلية، وهكذا أصبح طول الخلايا كما يأتي: من 1 إلى 1.66 يمنل غير موافق. من 1.67 وحتى 2.33 محايد من 2.34 وحتى 3.00 موافق.

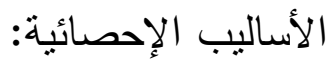

لتحقيق أهداف الدراسة وتحليل البيانات التي تم تجميعها، فقد تم استخدام أساليب

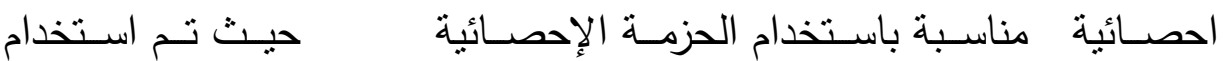
الانحراف المعياري؛ للتعرف على مدى انحراف استجابات أفراد الدراسة لكل عبارة من عبارات متغيرات الدراسـة، ولكل محور من المحاور الرئيسية عن متوسطها

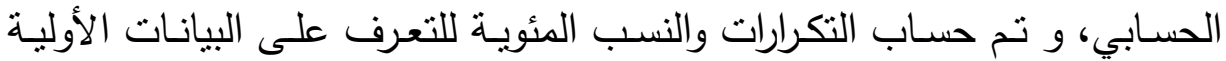
لأفراد الدراسة وتحديد استجابات أفرادها لكل عبارات من عبارات المحاور الرئيسة التي تتضمنها أداة الدراسة. 
الفصل الرابع

تمهيد: في هذا الفصل سـوف ينت عرض وتحليل النتائج وتفسيرها. مـن خـلال إجابة على أسئلة البحث هـث

جدول رقم (1) - (1)

يظهر من خلال جدول رقم (1) في تحليل العينة بأنه تتراوح أغلب أعمار أفراد

\begin{tabular}{|c|c|c|c|}
\hline النسبة & التكرار & & المتغير \\
\hline$\% 20$ & 8 & من 20سنة-30 سنة & \\
\hline$\% 32,5$ & 13 & مــن 30 ســنـة-40 & \\
\hline$\% 47,5$ & 19 & من40سنة-50 سنة & \\
\hline 0 & 0 & 10آلاف ريال أو أقل. & \multirow{4}{*}{ 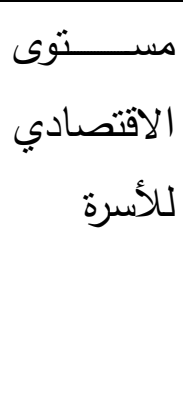 } \\
\hline$\% 22,5$ & 9 & 1آلاف ربال- 15 & \\
\hline$\% 35$ & 14 & 15ألف ربال-20ألف & \\
\hline$\% 42,5$ & 17 & أعلى مـن 20 ألـف & \\
\hline$\% 10$ & 4 & أسرة كبيرة & \multirow{3}{*}{ فئه التي يعيش الأسرة } \\
\hline$\% 50$ & 20 & أسرة منوسطة & \\
\hline$\% 40$ & 16 & أسرة صغيرة & \\
\hline
\end{tabular}

العينة من 30-50 سنة وهذا يعطي مصداقية أكبر لإجابات افراد عينة الدراسة،

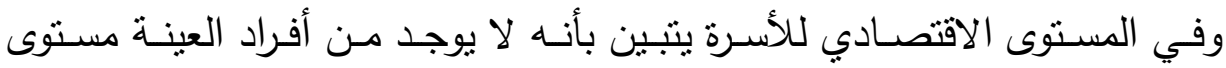

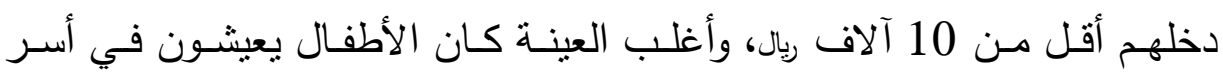
متوسطة الحجم وهذا ويعطي قوة لإجابات افراد عينة الدراسة. 


\section{جدول(2)}

\begin{tabular}{|c|c|c|c|c|c|c|c|}
\hline \multirow{2}{*}{ 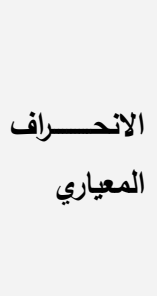 } & \multirow{2}{*}{ الحسابي } & \multicolumn{3}{|c|}{ 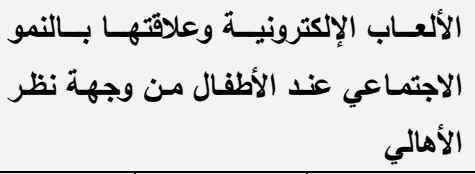 } & \multirow[b]{2}{*}{ \% } & \multirow[t]{2}{*}{ العبارة } & \multirow[t]{2}{*}{ b } \\
\hline & & غوافق & محايد & موافق & & & \\
\hline \multirow[t]{2}{*}{0.1} & \multirow[t]{2}{*}{2.5} & 17 & 18 & 5 & ك5 & \multirow{2}{*}{ 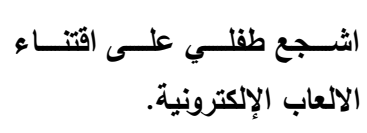 } & \multirow[t]{2}{*}{1} \\
\hline & & 42.5 & 45 & 12.5 & $\%$ & & \\
\hline \multirow[t]{2}{*}{0.2} & \multirow[t]{2}{*}{1.6} & 0 & 3 & 37 & ك5 & \multirow{2}{*}{ 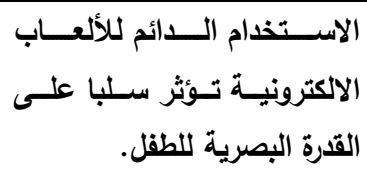 } & \multirow[t]{2}{*}{2} \\
\hline & & 0 & 7.5 & 92.5 & $\%$ & & \\
\hline \multirow[t]{2}{*}{0.3} & \multirow[t]{2}{*}{1.5} & 17 & 13 & 10 & ك5 & \multirow{2}{*}{ 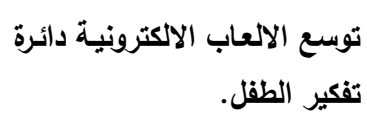 } & \multirow[t]{2}{*}{3} \\
\hline & & 42.5 & 32.5 & 25 & $\%$ & & \\
\hline \multirow[t]{2}{*}{0.7} & \multirow[t]{2}{*}{1.7} & 4 & 12 & 24 & ك5 & \multirow{2}{*}{ 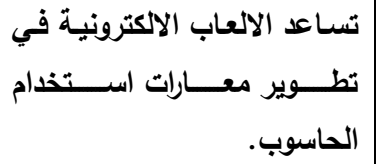 } & \multirow[t]{2}{*}{4} \\
\hline & & 10 & 30 & 60 & $\%$ & & \\
\hline \multirow[t]{2}{*}{0.14} & \multirow[t]{2}{*}{2.51} & 20 & 17 & 3 & ك5 & \multirow{2}{*}{ 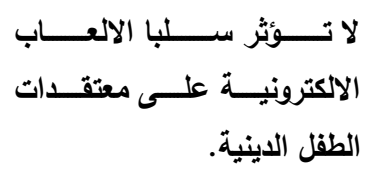 } & \multirow[t]{2}{*}{5} \\
\hline & & 50 & 42.5 & 7.5 & $\%$ & & \\
\hline \multirow[t]{2}{*}{0.25} & \multirow[t]{2}{*}{2.1} & 0 & 10 & 30 & ك5 & \multirow{2}{*}{ تشتجع الالعاب الاككترونية على العنف. } & \multirow[t]{2}{*}{6} \\
\hline & & 0 & 25 & 75 & $\%$ & & \\
\hline \multirow[t]{2}{*}{0.61} & \multirow[t]{2}{*}{1.8} & 5 & 11 & 24 & ك5 & \multirow{2}{*}{ تطوير مهارات الالعـاب الاكترونيـة في في اللفة } & \multirow[t]{2}{*}{7} \\
\hline & & 12.5 & 27.5 & 60 & $\%$ & & \\
\hline \multirow[t]{2}{*}{0.32} & 1.91 & 3 & 12 & 25 & ك5 & تســبب الالعـــاب الاكترونيــة & 8 \\
\hline & & 7.5 & 30 & 62.5 & $\%$ & للطفل السمنة الزائدة. & \\
\hline 0.62 & 2.6 & 1 & 7 & 32 & ك5 & تـؤدي الالعـاب الاكترونيـة إلى & 9 \\
\hline & & 2.5 & 17.5 & 80 & $\%$ & لأعمال اليومية. & \\
\hline
\end{tabular}

Doi : $10.12816 / 0053078$ 
مجلة الدراسات التربوية والانسانية ـ كلية التربية ـ جامعة دمنهور ـ المجلد العاشر - العدد الثانى - لسنة 2018

\begin{tabular}{|c|c|c|c|c|c|c|c|}
\hline \multirow[t]{2}{*}{0.71} & \multirow[t]{2}{*}{2.2} & 4 & 11 & 25 & ك & \multirow{2}{*}{ دائرة تفكير الطفل. الالكترونية تضيق مـن } & \multirow[t]{2}{*}{10} \\
\hline & & 10 & 27.5 & 62.5 & $\%$ & & \\
\hline \multirow[t]{2}{*}{0.62} & \multirow[t]{2}{*}{1.93} & 21 & 15 & 4 & ك5 & \multirow{2}{*}{ تشجعع الالعاب الاكترونية على مع الاخرين. } & \multirow[t]{2}{*}{11} \\
\hline & & 52.5 & 37.5 & 10 & $\%$ & & \\
\hline \multirow[t]{2}{*}{0.55} & \multirow[t]{2}{*}{1.74} & 26 & 9 & 5 & ك5 & \multirow{2}{*}{ 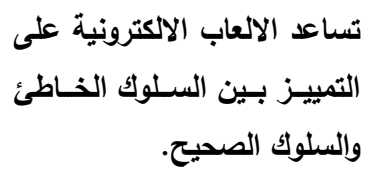 } & \multirow[t]{2}{*}{12} \\
\hline & & 65 & 22.5 & 12.5 & $\%$ & & \\
\hline \multirow[t]{2}{*}{0.14} & \multirow[t]{2}{*}{1.97} & 8 & 5 & 27 & ك5 & \multirow{2}{*}{ تالتحدي والالتنافس الاكترونية على الغير. } & \multirow[t]{2}{*}{13} \\
\hline & & 20 & 12.5 & 67.5 & $\%$ & & \\
\hline \multirow[t]{2}{*}{0.71} & \multirow[t]{2}{*}{1.44} & 32 & 5 & 3 & ك5 & \multirow{2}{*}{ ألاكتــــي الاولاد حريــة باللعـبـ من البنات. } & \multirow[t]{2}{*}{14} \\
\hline & & 80 & 12.5 & 7.5 & $\%$ & & \\
\hline \multirow[t]{2}{*}{0.80} & \multirow[t]{2}{*}{3.5} & 32 & 6 & 2 & ك5 & \multirow{2}{*}{ 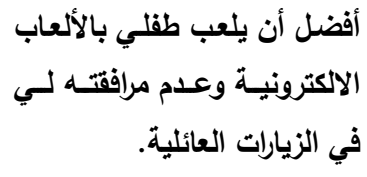 } & \multirow[b]{2}{*}{15} \\
\hline & & 80 & 15 & 5 & $\%$ & & \\
\hline \multirow[t]{2}{*}{0.87} & \multirow[t]{2}{*}{2.9} & 5 & 6 & 29 & ك & \multirow{2}{*}{ تفتقر الالعـاب الاكترونيـة إلى } & \multirow{2}{*}{16} \\
\hline & & 12.5 & 15 & 72.5 & $\%$ & & \\
\hline \multirow[t]{2}{*}{0.9} & \multirow[t]{2}{*}{2.5} & 2 & 4 & 34 & ك & \multirow{2}{*}{ تلعد الالعـاب الاكترونية وسيلة } & \multirow[b]{2}{*}{17} \\
\hline & & 5 & 10 & 85 & $\%$ & & \\
\hline \multirow[t]{2}{*}{0.91} & \multirow[t]{2}{*}{3.3} & 2 & 8 & 30 & ك & \multirow{2}{*}{ تؤئر الالعـاب الاكترونيـة سلبا } & \\
\hline & & 5 & 20 & 75 & $\%$ & & 10 \\
\hline 0.77 & 2.1 & 24 & 11 & 5 & ك5 & تسـاعد الألعاب الاككترونيـة في & \\
\hline & & 60 & 27.5 & 12.5 & $\%$ & تطوير التفكيـر المنطقـي وحلـل & 19 \\
\hline 0.75 & 2.8 & & & 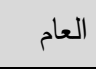 & ط الد & 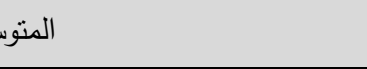 & \\
\hline
\end{tabular}

يوضتح الجدول(2) توزيع استجابات افراد الدراسة على العبارات، وقد بلغ المتوسط

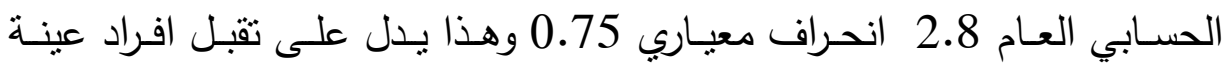


الدراسـة تجـاه لألعـاب الإلكترونيـة وعلاقتها بـالنمو الاجتمـاعي عند الأطفال مـن وجهة نظر الأهالي، وهذا يؤدي إلى قبولها. فيما يخص نتيجة السؤال الأول للدور الإيجابي الذي تقدمهـ الألعاب الإلكترونيـة للأطفال والتي أسفرت عن النتائج التالية: أظهرت نتائج البحث أن 60\% مـع أن الألعـاب الإلكترونيـة تسـاعد في تطوير مهارات استخدام الحاسوب وتطوير مهارات الطفل في اللغـة الإنجليزيـة وهذا مـا

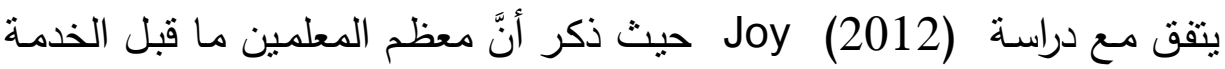

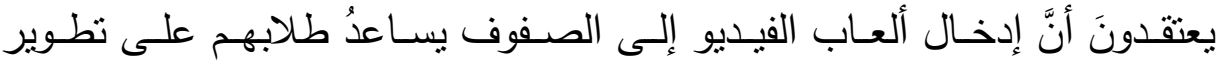
المهارات الأكاديميـة لديهم وتتفق أيضـا فيما أنثـار الفردان (2012) في الإطـار

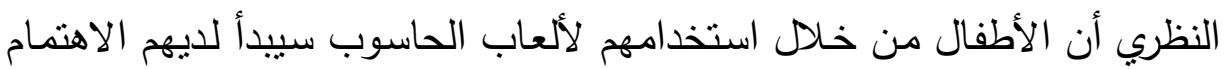
بالأجهزة الإلكترونية وتتطور مهارات اتصالهم بها.

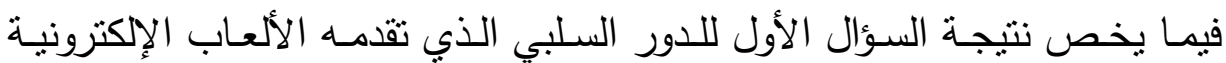
للأطفال والتي أسفرت عن النتائج التالية: اتفقت نتائج البحث مـع الدور السلبي للألعـاب الإلكترونيـة بنسبة 92,5\% مـن

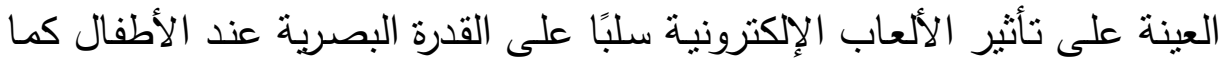
اتفق 62,5\% مـن العينة بـأن الألعـاب الإلكترونيـة تسبب السمنة الزائدة للطفل

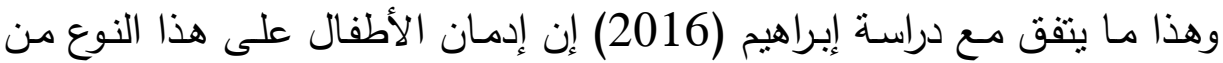
الألعاب يؤثز سلبا على قدرتهم البصرية ولياقتهم البدنيـة. وهذا مـا اتفق عليه محمد وحسن (2013، 2017) في الإطـار النظري مـن الأضـرار التي تسببها لهابها

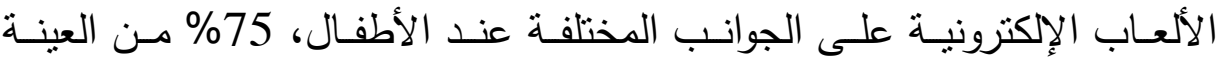
اظهرت اتفاقًا على الدور السلبي للألعاب الإلكترونية في نشجيعها على أعمال العنف عند الأطفال وهذا ما أكدت عليه نظرية التعلم الاجتماعي أنه من خلال المشاهدة الغير مباشرة لأعمال العنف يتأثر الطفل بها. 
فيمـا يخص نتيجـة السؤال الثالث عن مدى العلاقـة مـا بـين استخدام الألعـاب الإلكترونية والنمو الاجتماعي عند الأطفال والتي أسفرت عن النتائج التالية:

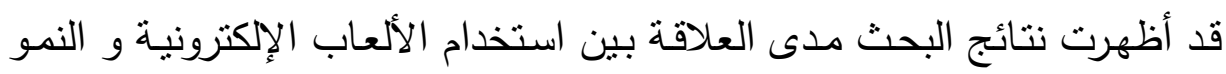

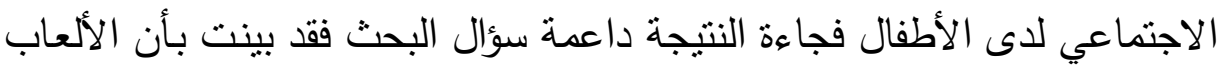
الإلكترونية لا تشجع على التعاون مع الآخرين و هذا ما ظهر من خـال النتائج

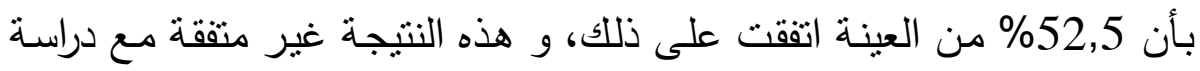

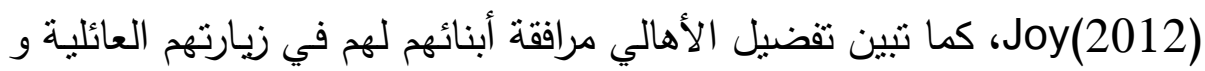

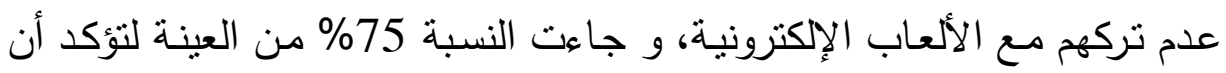

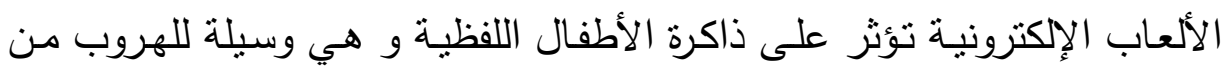
اللقاءات والاجتماعـات العائليـة، و البحث الحـالي ينـافي دراسـة أحمــ( 2012) التي وضحت عدم وجود مشاكل اجتماعية لدى الأطفال.

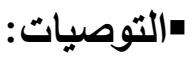

في ضوء النتائج التي أسفر عنها البحث الحالي توصلت الباحثة إلى مجموعة من التوصيات وهي: أولا: فيما يخص نتائج السؤال الأول ما الدور الإيجابي الذي ينتج عن الألعاب الإلكترونية على الأطفال، والتي أسفرت على اتفاق نتائج أداة البحث كالتي: تساعد الألعاب الإكترونية في تطوير استخدام الحاسوب وتعلم اللغة الإنجليزيـة لاى الأطفال؛ وتوصي الباحثة:

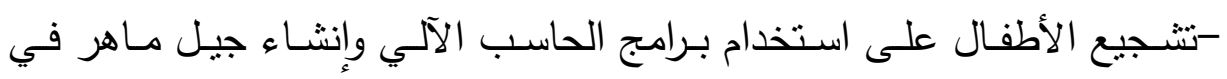
استخدام التقنية وهذا ما يتوافق مع رؤية المملكة 2030.

- نطوير مبدأ التعلم عن طريق اللعب وذللك بتحميل برامج تعليمية إنجليزية مسلية

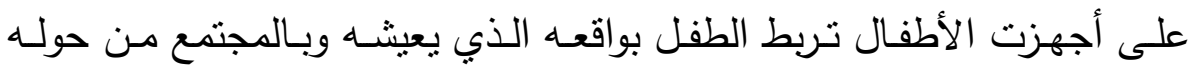
بطربقة جذابة. 
ثانيا: فيما يخص نتائج السؤال الثاني ما الدور السلبي الذي ينتج عن الألعاب الإكترونية على الأطفال، والتي أسفرت على اتفاق نتائج أداة البحث كالتي:

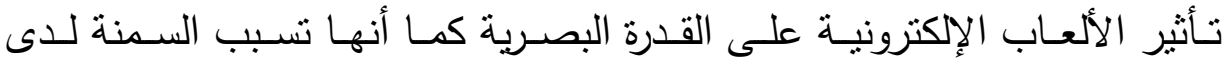
الأطفال، وتمنع الطفل من تكوين صداقات مع أقرانه؛ فتوصي الباحثة: -بتجهيز مكان مناسـب لجلوس الأطفال أثناء استخدامهم للألعـاب الإلكترونيـة لتقليل الآثار السلبية على صحتهم.

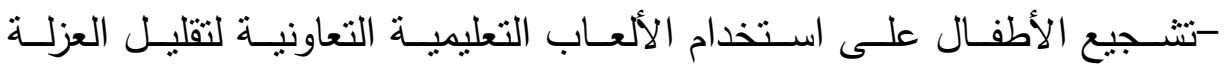
الاجتماعية والأنانية لدى الطفل.

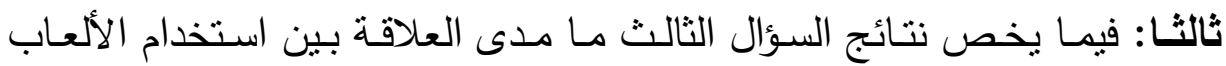
الإككترونية والنمو الاجتماعي عند الأطفال: إن الألعاب الإكترونية تسبب هروب الأطفال من اللقاءات والاجتماعات العائلية

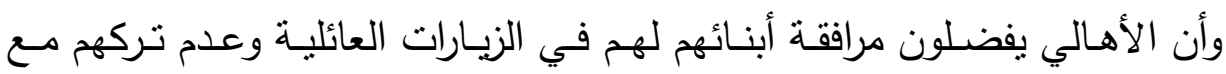
الألعاب الإلكترونية وحدهم؛ نوصي الباحثة: -بضرورة الحد من استخدام الألعاب الإلكترونية وتحديد ساعات معينة يسمح فيها للأطفال باستخدام الألعاب والبرامج الإلكترونية المفيدة.

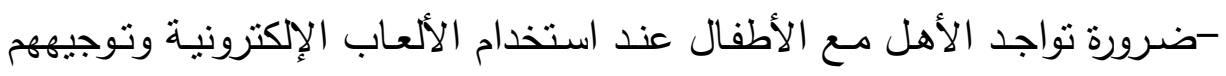
حيال الاستخدام الجيد لهذه الألعاب. المقترحات: بناء على النتائج التي توصل إليهه البحث، تقترح الباحثّة إجراء دراسـات أخرى تتتاول: - الألعاب الإلكترونية وعلاقتها في النمو النفسي لدى الطفل. -الألعاب الإلكترونية وعلاقتها في النمو الاجتماعي لدى الأطفال البيئات الفقيرة. -الألعاب الإلكترونية وعلاقتها في النمو الاجتماعي لدى المراهقين. 


\section{المراجع العربية}

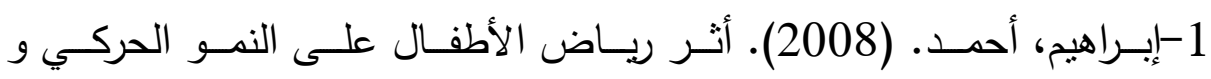

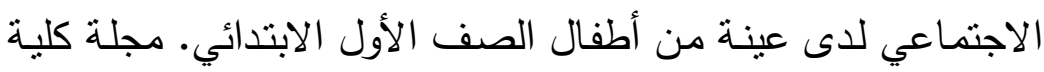

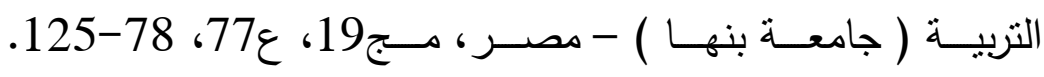

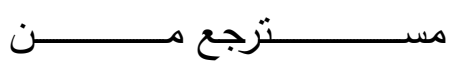

http://search.mandumah.com/Record/45823

2-إبراهيم، نداء. (2016). إيجابيات الألعاب الإلكترونية التي يمارسها أطفال

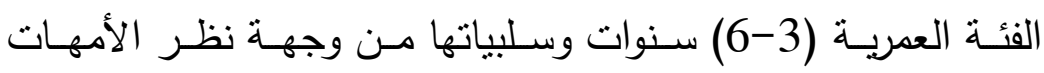

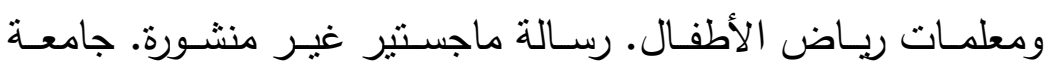

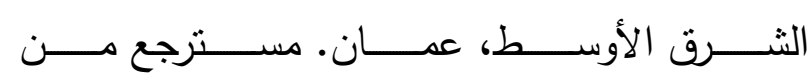

http://search.mandumah.com/Record/722203

3-أبو جادو، صالح. (2015). سيكولوجية التشئة الاجتماعية.(ط11)، عمان:

$$
\text { دار الميسرة. }
$$

4-أبو عايش، إسماعيل. (2015). النمو الاجتماعي وعلاقته بالتعاطف النفسى

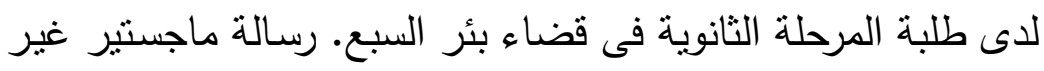

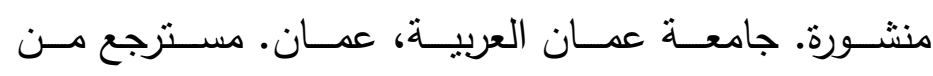
http://search.mandumah.com/Record/788331 5-أحمد، سناء. (2017). عولمـة تكنولوجيا الاتصـال وعلاقتها بتغير منظومـة

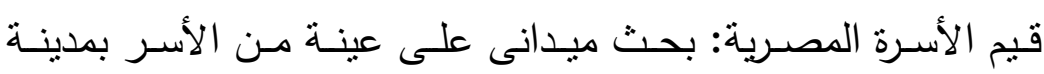

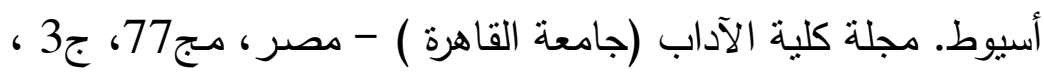

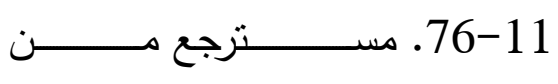

http://search.mandumah.com/Record/846313 
الألعاب الإكترونية وعلاقتها بالنمو الاجتماعي غذ الأطفال من وجهة نظر الأهالي .شه إيراهيم الفلح

6-أحمد، فـايزة. (2016). الألعـاب الإلكترونيـة وعلاقتها ببعض الإضطرابات

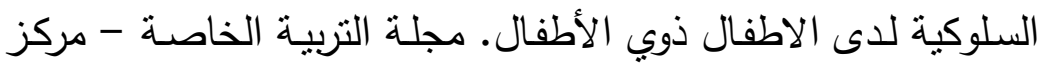

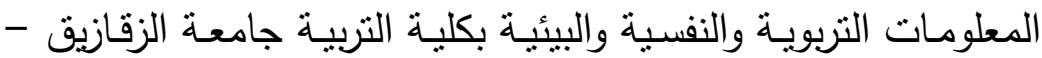

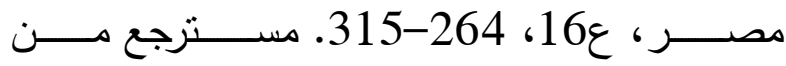

http://search.mandum 